\title{
Entrepreneurs' Social Network and Corporate Risk Contagion: A Dynamic Evaluation and Simulation Approach
}

\author{
Yang Yang $\mathbb{D}^{1},{ }^{1}$ Qian Qian $\mathbb{D}^{2}{ }^{2}$ and Zheng Li $\mathbb{D}^{1}$ \\ ${ }^{1}$ School of Economic Mathematics, Southwestern University of Finance and Economics, No. 555 Liutai Avenue, \\ Wenjiang District, Chengdu 611130, China \\ ${ }^{2}$ School of Business, Sichuan Normal University, Chengdu 610101, China \\ Correspondence should be addressed to Qian Qian; qianqianfeng@163.com
}

Received 15 October 2020; Revised 29 November 2020; Accepted 8 December 2020; Published 21 December 2020

Academic Editor: Y. T. Peter Bian

Copyright (C) 2020 Yang Yang et al. This is an open access article distributed under the Creative Commons Attribution License, which permits unrestricted use, distribution, and reproduction in any medium, provided the original work is properly cited.

\begin{abstract}
Interactions of entrepreneurs through social networks provide an available path for corporate risk contagions. However, the issue how entrepreneurs' social networks influence on corporate risk contagion is still received limited attention from scholars. In this study, a framework is proposed to describe entrepreneurs' interaction and corporate value creation. The main results of multiagent simulations indicate the following. First, either weak ties or strong connections of social networks can enhance density of corporate risk contagion. However, only strong connections can be moderated by entrepreneurs' risk preference. Second, weak ties improve risk exposure of individual corporations, while strong connections may probably decrease systematical risk of the market. Third, weak ties are important for mature corporations to achieve business success. However, for startups, strong connections are more valuable to maintain. The findings of this study not only provide theoretical support from some widely accepted economic phenomenon but also provide explanations for conflicting results from some previous literatures.
\end{abstract}

\section{Introduction}

Social network has been playing an increasingly important role in shaping decision-making of entrepreneurs and consequently influences on corporate strategies in many ways [1]. According to socio-cultural theories, an entrepreneur often adopts the attitudes or behaviors of others in his social networks $[2,3]$. The basic idea is that the entrepreneur or top managerial function is inserted and developed within networks of social relationship [4]. Previous studies in management also highlighted the influence of social networks on entrepreneurs' decisions $[5,6]$. These studies focused on the norms generated by social networks and illustrated that investment and risk management strategies of entrepreneurs which mutual connected in social networks are likely to converge $[7,8]$. Using analogous reasoning, corporate risk derived from corporate behavior may probably spread from one corporation to another through social networks of their entrepreneurs.
The relevance of social networks and statical corporate risk has been discussed by a number of scholars, including Ferris et al. [9], Hartmann and Herb [10], and Ho et al. [11]. This interest has in part been driven by the insight that interactions of entrepreneurs through social networks influence corporate strategies. Most of this stream of literatures argued that social networks not only provide an informal insurance for investment of corporations but also breed ambitions and desires of entrepreneurs which lead to a high level of corporate risk. Despite the evidence that social networks have positive effects on corporate risk exposure, some critical voices showed that the larger an entrepreneur's social network of relation, the more financial support can be accessed when financial accident occurred. Although there are still conflicting views on the influence of social networks on corporate risk, the consensus is that entrepreneurs' social networks indeed play an important role in corporate risk strategies. Generally speaking, the prior studies provide strong support for the role of entrepreneurs' social networks in corporate strategies and consequently influence the 
corporate risk. However, almost all of these studies considered corporate risk statically, and the research studies on process and consequence of corporate risk contagion with dynamic perspective are still limited.

Moreover, as a matter of fact, entrepreneurs' network consists of a mixture of weak ties and strong connections $[12,13]$. Whether a connection between two entrepreneurs in social network can be seemed as weak ties or strong connections depends on density of interactions between these entrepreneurs, including frequency, nature, and emotional intensity of the interactions. Following prior studies and their conclusions, strong connections provide entrepreneurs critical resources and opportunities, which often crucial for their strategic decisions, while weak ties offer entrepreneurs more diverse information [14]. Compared with strong connections, weak ties pave the way for fresher and more unique information although redundant information often abounds with weak ties [15]. Originating from these works on functions of strong connections and weak ties, we reasonably expect that the influence of strong connections on corporate risk contagion may be very different from it of weak ties.

In this study, a novel mathematical framework is used that takes a systematic perspective to dynamically describe the interactions of entrepreneurs through social networks and processes of corporate risk. This framework includes key factors drawn from the literature, such as strong connections and weak ties, process of strategic decision-making, and financial support through networks and provides an extensible structure to help us understand the influence of entrepreneurs' social networks on corporate risk contagion. Our review of the literature indicates that we are among the first to investigate influence of social networks with such framework. According to the framework, multiple numerical simulations are conducted. The results of the simulations show several notable results. First, entrepreneurs' social network including both strong connections and weak ties can be seemed as an important path for corporate risk contagions. Moreover, risk preference of entrepreneurs positively moderates this function of strong connections but not sensitive to it of weak ties. Second, the role played on corporate risk of strong connections and weak ties is different. Weak ties of entrepreneurs lead corporation display relative high level of risk exposure, while strong connections can help decrease the systematical risk of the whole market. Third, the weak ties may probably motivate entrepreneurs intend to adopt more riskier investment strategies. And finally, weak ties are crucial factors of business success for mature corporations, while strong connections are more valuable to maintain for startups.

This study contributes to previous literatures in three ways. First, it adds to the emerging literature on the influence of social networks on corporate strategies or entrepreneurs' decision-making. Unlike prior studies, we use a dynamic perspective to investigate effects of social networks on the board issue of corporate risk contagion, including processes and consequences of corporate risk contagions. Second, the simulation approach used in this study provides an alternative method for validating previous studies. The results derived from our simulations also complement the findings of prior literatures and can, to an extent, explain the conflicting conclusions of some research studies. In addition, we shed light on social network maintaining and strategic decision-making of entrepreneurs to achieve their business success. And finally, the framework proposed in this study can easily extend to explain some of the classical economic phenomena concerning influence of entrepreneurs' social networks.

The rest of the paper is organized as follows. Section 2 is a review of literatures pertaining to social networks of entrepreneurs and corporate risk contagion. In Section 3, we introduce main notations and assumptions and explain the construction of the mathematical framework for describing entrepreneurs' behaviors of investment and evolution of market. The simulations and the results analysis are reported in Section 4. In Section 5, our framework is extended to include more realistic factors for consideration. At last, the conclusions and discussions of these studies are represented in Section 6.

\section{Literature Review}

In this section, we review the literature related to our study from two aspects: social networks of entrepreneurs and corporate risk contagion.

2.1. Social Networks of Entrepreneurs. The concept of social network is distinct from, but convergent with, the idea of social capital because the social capital is always created, maintained, and accessed through social networks [9]. Although the definitions of generalized social networks vary as per context of scholars defining it across the literature [16], in most management literatures, entrepreneurs' social network is defined as a set of entrepreneurs linked by a set of social relationships, such as kinship, friendship, and cooperative partners of a specific type [17]. The previous studies on social capital highlighted the influence on managerial or entrepreneurs' decisions of social networks. They argued that the corporate decisions are made by entrepreneurs or managers rather than firms themselves [18]. Therefore, the social networks linked entrepreneurs are likely to affect the strategies adopted by corporations. For example, Postelnicu and Hermes [19] found the success of a large part of the loan between corporations and financial institutions depends on interactions and information derived from mutual social networks, especially for those microfinance institutions. Hasan et al. [20] ascertained that the density of social networks in the U.S. is positively associated with innovation of corporations. In addition, using a comprehensive sample of approximately 15,425 cross-country observations for 4 years [21] showed that the political leanings of social networks significantly affect entrepreneurs' decisions and thereby influence corporate strategies. In addition, other scholars also documented the role of social networks on entrepreneurs' decision-making processes [22-26] and corporate strategies, such as financial policies [27], corporate value creation [28, 29], market competition [30, 31], 
executive compensation [32], and capital structure [33]. As investigated by previous studies, one can conclude that social networks influence entrepreneurs' decision-making and consequently affect corporate strategies in many ways.

In the perspective of corporate risk, numerous previous studies documented that the entrepreneurs' social network may probably induce uncertainty and change risks faced by corporations [9]. Most scholars believe that social networks essentially provide entrepreneurs an informal insurance which can significantly motivate them to adopt more aggressive and risky investment strategies [19, 34, 35]. Brass and Burkhardt [36, 37] and Hoi et al. [38] empirically examined the behavior of corporate headquarters and argued that the perceived power of entrepreneurs is enhanced with increasing of their embeddedness of social networks and subsequently impels entrepreneurs take more risk in their investment. In addition, the similar results are concluded by Hirshleifer and Thakor [39] and Schneider [40] from agency theory. In addition, prior studies in corporate finance also discussed the factors which moderate the influence of social networks on corporate risk. Stulz [41] and Niu and Chen [42] discussed the moderated effects of corporate governance. They showed that reasonable governance structure of corporation can lead to a more appropriate corporate risk using cross-country and regional data, respectively. Acemoglu and Zilibotti [43] and Javakhadze et al. [44] proved that the positive relationship of social networks and corporate risk can be weakened in the areas with developed financial market. This is the result of mechanism of efficient risk-sharing in these areas. In addition, the moderated effects by external institutional environment, such as investor protection and culture tradition, are also considered by some literatures [45-47]. Nevertheless a few scholars provide conflict conclusions of the influence of social networks on corporate risk. They argued that social norms brought by social networks induce entrepreneurs behave more prudential and decrease their inclination of opportunistic behavior [48, 49]. In general, a rich literature across several disciplines documented influence of social networks on corporate risk. However, almost all these studies considered corporate risk statically. The research on process and consequences of corporate risk contagion is still in its preliminary stage.

2.2. Corporate Risk Contagion. The research studies of corporate risk contagion are a specific context that have been beneficiating from the steady increase in scholarly work on financial contagions since 1990s, especially after subprime crisis of 2008 [50]. The early work of corporate risk contagion tried to clarify the concept of risk corporation. For example, Lucas [51] defined the corporate risk contagion as the relationship between default of one corporation with that of the other. In addition, Gersbach and Lipponer [52] considered the corporate risk contagion as the correlation of volatility of assets value between corporations. Some prior studies focused to exam the risk contagion among corporations. Davis and Lo [53] proposed a mathematical model to investigate whether corporate risk affects its affiliated corporations. Chen et al. [54] and Jarrow and Yu [55] revealed specific types of risk contagion among corporations according to reduced-form models. Using banking loan origination data, Cai et al. [56] also provided empirical evidence of corporate risk contagion in bank-corporation networks. Another stream of studies which include a rich literature in management science documented methodology of corporate risk contagion. Zhou [57] employed the structure model to describe risk contagion between corporations, while Yu et al. [58] used the reduced-form model to examine corporate risk contagions. The vector autoregression (VAR) model and principal component analysis (PCA) were used by Jin and Francisco [59] and Kang and Yoon, [60], respectively, to measure risk contagion through capital market. Correlation coefficient and copula functions are two popular approaches introduced by many scholars to measure risk contagions [61-63]. In addition, building on these approaches, numerous of improvements have been made to make the measurement more accurate $[64,65]$. More recent approaches to measure risk contagion include event studies [66], Markov methods [67], co-kurtosis model [68], and big data analysis [69].

In addition, based on the above research methodology, the mechanism behind corporate risk contagion is widely explored by scholars. Giesecke and Weber [70] modeled credit losses on portfolios of financial positions contracted with corporation subject to direct risk contagion processes and showed that corporate risk contagion is associated with the local interactions of corporations with their business partners. This result is empirically confirmed by Jorion and Zhang [71] through manually collecting information of bankruptcies occurred during 1999 to 2005. Sui and Li [72] argued that guarantee relationships are determinant for corporate risk contagions in most cases, while Chakrabarty and Zhang [73] highlighted influence of market structure on risk contagions. Besides, other factors including income structure [74], topology of corporate networks [75], and industrial environment [76] are proved to be playing important roles in corporate risk contagion. Thus, previous studies and their findings contribute a lot to various aspects of corporate risk contagions. However, the relationship between social networks and corporate risk contagion has still received limited attentions of scholars so far.

\section{Modeling Description}

Considering the interaction of entrepreneurs and the process of corporate value creation, a framework is proposed to describe how social networks influence on entrepreneurs' decision-making and consequently on corporate risk contagion.

3.1. Model Notations. The main variables that we used in this study are listed in Table 1.

According to Table 1, $N$ and $m$ represent the number of corporations (one corporation correspond to one entrepreneur) and venture projects in the market. The following relationship exists: $e_{i} \in \mathbb{E}, \quad c_{i} \in \mathbb{C}, \quad p_{i} \in \mathbb{P}, \quad$ and 
TABLE 1: Notations in model.

\begin{tabular}{|c|c|}
\hline Decision variables & Explanation \\
\hline $\begin{array}{l}\mathcal{E}_{t}^{\mathrm{ki}}, k \in\{w, s\} \\
\lambda^{i} \\
D\end{array}$ & $\begin{array}{c}\text { Effort made by entrepreneur } e_{i} \text { to maintain his social network at period } t \\
\text { Proportion of cash invested in venture projects by corporation } c_{i} \\
\text { Influence radius of venture projects }\end{array}$ \\
\hline $\begin{array}{l}\text { Control variables } \\
R \\
A \\
B\end{array}$ & $\begin{array}{c}\text { Risk-free interest rate } \\
\text { Parameter of entrepreneurs' cost function } \\
\text { Parameter for entrepreneurs seeking for help when financial accident occurred }\end{array}$ \\
\hline $\begin{array}{l}\text { Statistical variables } \\
W_{t}^{{ }^{i}} \\
r_{t}^{{ }^{i}} \\
\Delta_{t}{ }^{i} \\
L_{t}{ }^{i} \\
\chi_{T} \\
\phi_{T}{ }^{i} \\
\rho_{T^{i}} \\
\gamma_{t}{ }^{\mathrm{ki}}, k \in\{w, s\} \\
\varphi_{T}{ }^{\mathrm{ki}}, k \in\{w, s\} \\
\omega T^{\mathrm{ki}}, k \in\{w, s\} \\
\end{array}$ & $\begin{array}{c}\text { Capital possessed by corporation } p_{i} \text { after period } t \\
\text { Realized return of venture project } p_{i} \text { after period } t \\
\text { Decision bias of entrepreneur } e_{i} \text { at period } t \\
\text { Total amount funded to corporation } c_{i} \text { at his financial accident period } t \\
\text { Survival rate of corporations that measures system risk during time interval }[0, T] \\
\text { Probability of expected loss that measures individual risk of } c_{i} \text { during time interval }[0, T \\
\text { First time corporation } c_{i} \text { suffers financial accident during time interval }[0, T] \\
\text { Degree of centrality of corporation } c_{i} \text { in social networks at period } t \\
\text { Embeddedness of corporation } c_{i} \text { in his social networks during time interval }[0, T] \\
\text { Spillover effect of social networks of corporation } c_{i} \text { during time interval }[0, T]\end{array}$ \\
\hline
\end{tabular}

Functions

$d\left(c_{i}, p_{j}\right)$

$K_{t}^{i}\left(\varepsilon_{t}^{i j}\right), i \in\{w, s\}$

$C\left(\varepsilon_{t}{ }^{\mathrm{wi}}, \varepsilon_{t}^{\mathrm{si}}\right)$

$\pi\left(c_{i}, t\right)$

Sets

$\mathbb{E}$

$\mathbb{C}$

$\mathbb{P}$

$C_{t}^{i}$

$H_{t}{ }^{i}$

$A_{t}{ }^{i}$

$L_{t}^{\mathrm{ki}}, k \in\{w, s\}$

$J_{t}^{i}$

$B_{t}{ }^{i}$

$D_{t}{ }^{i}$

Other notations

$e_{i}, i \in\{1,2, \ldots, N\}$

$c_{i}, i \in\{1,2, \ldots, N\}$

$p_{i}, i \in\{1,2, \ldots, m\}$

$\mathscr{J}_{t}^{i} \subseteq \mathscr{C}_{t}^{i} \subseteq \mathscr{A}_{t}^{i} \subseteq \mathbb{C}, \mathscr{L}_{t}^{k i} \subseteq \mathbb{E}$, and $\mathscr{B}_{t}^{i} \subseteq \cup_{t=0}^{t-1} c_{t}^{i}$. The statistical variables in Table 1 describe information that should be captured from process of simulation.

\subsection{Model Assumptions}

Assumption 1 (A1). The market is constituted by various venture projects and corporations. Each corporation is controlled and operated by a specific entrepreneur, and all the entrepreneurs form the entrepreneurs' social network.

Entrepreneurs' decision-making regarding corporate investment, financing, and strategies is often influenced by people hanging from their social networks, especially those successful entrepreneurs who had close relationship to them. In addition, according to previous studies pertaining to social capital $[15,77]$, the social network that influences entrepreneurs' decision-making can be further summarized in two types due to the different paths of influence. One is
Distance of corporation $c_{i}$ and venture project $p_{j}$ Cost for entrepreneurs to maintain their social networks Expect return of investment of corporation $c_{i}$ at period $t$
Set of entrepreneurs

Set of corporations

Set of venture projects

Set of venture projects in which corporation $c_{i}$ invests at period $t$

Set of venture projects that can be directly accessed by corporation $c_{i}$ at period $t$

Negative list of venture projects for entrepreneur $e_{i}$ after period $t$

Specific entrepreneur whose identity is represented by subscript

Specific corporation whose identity is represented by subscript

Specific venture project whose identity is represented by subscript called weak ties social networks, and the other is strong connections social networks. To capture this nature, we assume that there are $N$ corporations, which correspond to $N$ entrepreneurs in the market. In addition, the entrepreneurs' social network is described as a dual layer network. Specifically, we consider $N$ entrepreneurs as $N$ vertices, which are randomly distributed on a coordinate plane initially. In addition, for each vertex, $K_{t}^{w}\left(K_{t}^{s}\right)$ edges then connecting with other vertices are generated at each period $t$, which lead to a "small-world" networks [78]. $K_{t}^{w}$ and $K_{t}^{s}$ are functions of $\varepsilon_{t}^{w i}$ and $\varepsilon_{t}^{s i}$, respectively, where $\varepsilon_{t}^{w i}\left(\varepsilon_{t}^{s i}\right)$ measures the effect made by entrepreneur $e_{i}$ to maintain his weak ties (strong connection) social network at period $t$. Functions $K_{t}^{w}$ and $K_{t}^{s}$ measure tightness of weak ties social network and strong connections social network at each period $t$, respectively.

In addition, we make $m$ venture projects randomly distributed in a coordinate plane over which corporations are spread. In order to describe the process of which 
corporations invest in these venture projects, we define distance for each pair of corporation and venture project $d\left(c_{i}, p_{j}\right), c_{i} \in \mathbb{C}, p_{j} \in \mathbb{P}, i \in\{1,2, \ldots, N\}, j \in\{1,2, \ldots, m\}$. This distance measures cost of accessing information of venture project $p_{j}$ for corporation $c_{i}$. For example, the inequality $d\left(c_{i}, p_{j}\right)>d\left(c_{i}, p_{k}\right)$ represents that corporation $c_{i}$ is more familiar with venture project $p_{k}$ compared with venture project $p_{j}$. This may due to regional advantages, strategic selection, or industrial agglomeration. For a specific corporation, venture projects those with a distance far away would not even be under consideration for invest by him.

Figure 1 illustrates the social networks of entrepreneurs and the relationship between corporations and venture projects in general.

Assumption 2 (A2). Corporations create value for shareholders by investing venture projects in the market. In addition, the investment process is influenced by both weak ties social network and strong connections social network of entrepreneurs through different paths.

Without loss of generality, the return rate of a specific venture project $p_{i}, i \in\{1,2, \ldots, m\}$ is a private information that supposed to be subjected to a normal distribution $N\left(\mu_{i}, \sigma_{i}\right)$. Drawing on Yang et al. [79], we denote the realized return of venture project $p_{i}$ at period $t$ as $r_{i}$ and the investment strategy of corporation $c_{i}$ as a binary $\left(\lambda^{i}, \mathscr{C}_{t}^{i}\right)$, where $\lambda^{i} \in[0,1]$ represents the proportion of cash invested in venture projects and $\mathscr{C}_{t}^{i}$ denotes the set of venture projects in which corporation $c_{i}$ invests at period $t$. Assuming investment amount of corporation $c_{i}$ at period $t$ is equally invested for the venture projects $p_{i} \in \mathscr{C}_{t}^{i}$, each project $p_{i} \in \mathscr{C}_{t}^{i}$ can obtain $\left(\lambda^{i} W_{t-1}^{i}\right) /\left|\mathscr{C}_{t}^{i}\right|$, where the capital possessed by corporation $p_{i}$ at the end of period $t$ is denoted as $W_{t}^{i}$ and $\left|\mathscr{C}_{t}^{i}\right|$ measures the number of elements in set $\mathscr{C}_{t}^{i}$. If risk-free interest rate is $r$, risk-free return for corporation $c_{i}$ can be obtained as $\left(1-\lambda^{i}\right)(1+r) W_{t-1}^{i}$ at period $t$. Therefore, the investment strategy $\left(\lambda^{i}, \mathscr{C}_{t}^{i}\right)$ also illustrates the risk attitude for corporations. Those who have relatively large $\lambda^{i}$ can be seen as more risk preference.

Following previous literatures $[13,80,81]$, every entrepreneurs' social network consists of a mixture of weak ties and strong connections. In addition, the weak ties and strong connections may play different roles on impacting entrepreneurs' strategic decisions. It costs more time, energy, and money to maintain the strong connections through which entrepreneurs can obtain investment opportunities and critical support in their difficult circumstance. While on the other hand, maintaining weak ties may only depend on infrequent interaction and nonaffective emotional intensity. However, as argued by many scholars [82], weak ties are not dispensable. It provides entrepreneurs information pertaining to venture projects which can sometimes play a decisive role in business success. In order to capture these natures of both weak ties and strong connections, the set of venture projects invested by corporations $\mathscr{C}_{t}^{i}$ is supposed to be generated through three steps. First, all the venture projects accessible to corporation $c_{i}$ at period $t$ constitute alternative set that may be considered to be invested by the corporation. Denoting the venture projects that can be directly accessed by corporation $c_{i}$ at period $t$ as $\mathscr{H}_{t}^{i}=\left\{p_{j} \in \mathbb{P} \mid d\left(c_{i}, p_{j}\right)<\bar{d}\right\}$ and the set of entrepreneurs with whom entrepreneur $e_{i}$ connects at period $t$ in weak ties networks and strong connection networks as $\mathscr{L}_{t}^{w i}$ and $\mathscr{L}_{t}^{s i}$, respectively, the alternative set of venture projects for corporation $c_{i}$ at period $t$ can be represented as follows:

$$
\mathscr{A}_{t}^{i}=\bigcup_{e_{j} \in \mathscr{L}_{t}^{s i}} \mathscr{H}_{t}^{j} \cup \mathscr{H}_{t}^{i} .
$$

According to equation (1), $\mathscr{A}_{t}^{i}$, the investment opportunities for corporation $c_{i}$ at period $t$ consisted of two parts. One is the venture projects that directly contacted by entrepreneur $e_{i}$ himself and the other comes from strong connections social networks of entrepreneur $e_{i}$. Therefore, the decisive impact of strong connections of entrepreneurs on their investment, providing coinvestment opportunities, is described by equation (1).

The entrepreneur $e_{i}$ then decides which venture projects he would be invested in at period $t$ from his potential opportunities. In this decision process, entrepreneur's personal experience and weak ties network may play a rather important role. We denote $\mathcal{F}_{t}^{i}=\left\{p_{j} \in \mathscr{C}_{t}^{i} \mid r_{t}^{i}<r\right\}$. It includes the venture projects which are invested by corporation $c_{i}$ at the beginning of period $t$, and their realized returns are lower than risk-free rate $r$ at the end of period $t$. Using $\mathscr{B}_{t}^{i}=$ $\cup_{t=1}^{t} \mathscr{F}_{t}^{i}$ to represent the knowledge accumulation for entrepreneur $e_{i}$ in his investment career, the $\mathscr{B}_{t}^{i}$ can be also measured as a "negative list" before entrepreneur's invest. Consistent with conclusions of numerous literatures $[83,84]$, we argue that sharing information through weak ties is the most important factor that weak ties social network influences entrepreneurs' investment decisions. Combining with the potential investment opportunities, the venture projects invested by corporation $c_{i}$ at period $t$ can be represented as follows:

$$
\mathscr{C}_{t}^{i}=\frac{\mathscr{A}_{t}^{i}}{\left[\cup_{e_{j} \in \mathscr{L}_{t}^{w i}} \mathscr{B}_{t}^{j} \cup \mathscr{B}_{t}^{i}\right]} .
$$

Equation (2) describes how weak ties network influences entrepreneurs' investment through information sharing. Entrepreneurs who occupied the dense position in weak ties social network can receive more information pertaining to venture projects and consequently invest more precise and effective. It is worth noting that selecting venture projects based on information from either entrepreneur himself or his weak ties networks is not an optimal decision since the realized return of a specific venture project is subject to a random distribution. Nevertheless, this decision model is a dynamic optimization process with increasing of investment experience. Theoretically, this investment decision model can help the entrepreneur continuously improve his investment performance.

Assumption 3 (A3). Entrepreneurs maintain their social networks to maximize their expected return on investment.

According to A1 and A2, social networks including both weak ties and strong connections can either provide entrepreneurs new investment opportunities or help 


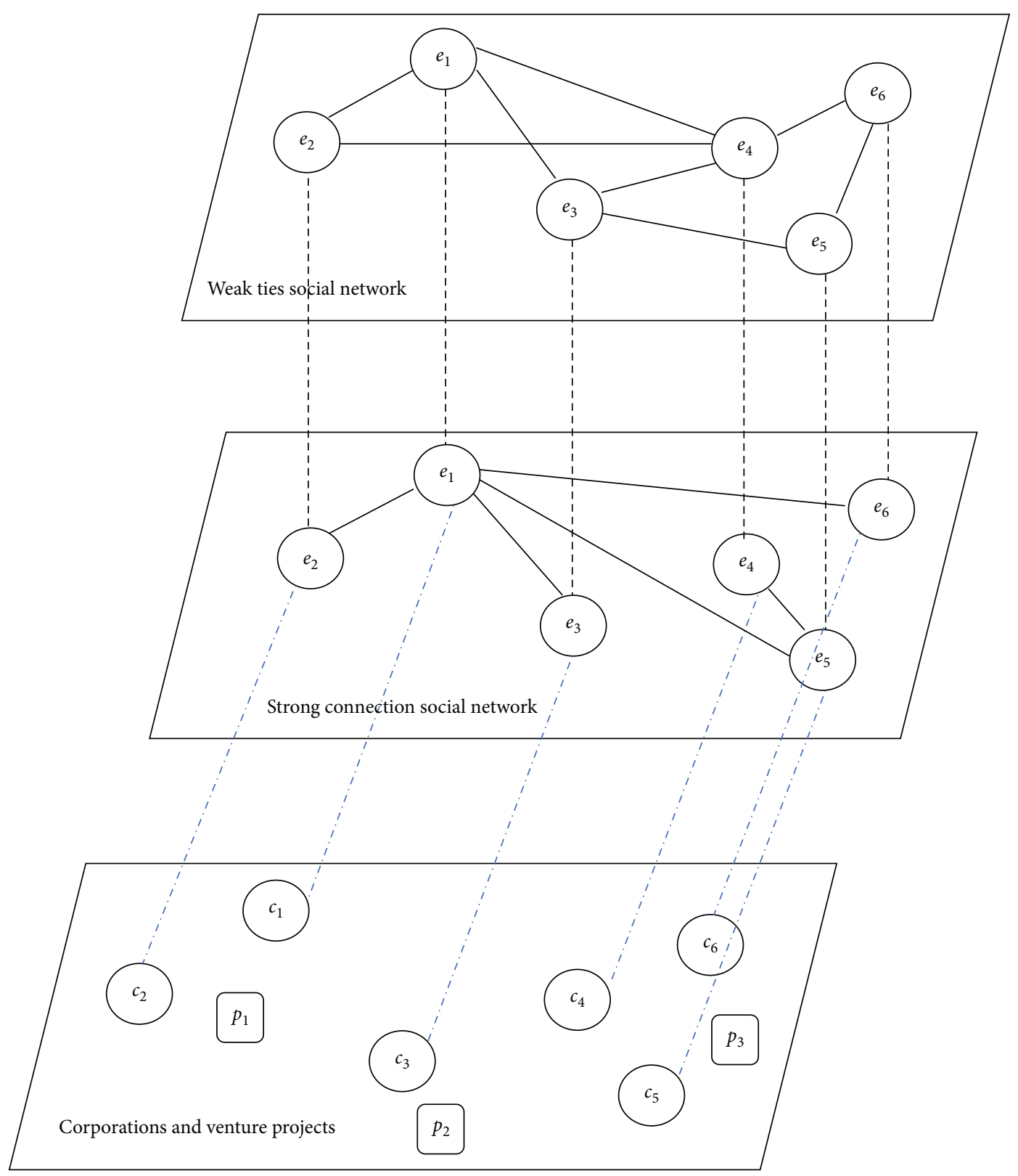

FIGURE 1: Corporations, venture projects, and social network of entrepreneurs.

entrepreneurs with venture projects risk identification. However, it also costs for entrepreneurs to maintain their social networks. Following Lv et al. [85] and Xu et al. [86], the Cobb-Douglas function [87] is proposed to describe entrepreneurs' cost for maintaining their social network.

$$
C\left(\varepsilon_{t}^{w i}, \varepsilon_{t}^{s i}\right)=\left(\varepsilon_{t}^{w i}\right)^{\alpha}\left(\varepsilon_{t}^{s i}\right)^{1-\alpha},
$$

where $\varepsilon_{t}^{k i}, k \in\{w, k\}$ is the effort made by entrepreneur $e_{i}$ to maintain their weak ties or strong connection networks, and the parameter $\alpha \in(0.5,1)$ captures the fact that strong connection networks are maintained more cost compared with weak ties networks.

Therefore, the expected return on investment of corporation $c_{i}$ at period $t$ is represented as follows:

$$
\begin{aligned}
\pi\left(c_{i}, t\right)= & \sum_{p_{j} \in \mathscr{C}_{t}^{i}} \int_{-\infty}^{+\infty}\left(\lambda^{i} W_{t-1}^{i}\right) \frac{(1+x)}{\left|\mathscr{C}_{t}^{i}\right|} f_{j}(x) \mathrm{d} x \\
& +\left(1-\lambda^{i}\right)(1+r) W_{t-1}^{i}-\left(\varepsilon_{t}^{w i}\right)^{\alpha}\left(\varepsilon_{t}^{s i}\right)^{1-\alpha},
\end{aligned}
$$

where $f_{j}(x)$ is the density function of investment return of venture project $p_{j}$.

According to equation (4), at the beginning of each period $t$, the optimal decision of entrepreneurs can be calculated by problem (5) through the numerical method.

$$
\max _{\varepsilon_{t}^{k i}, k \in\{w, s\}} \pi\left(c_{i}, t\right) .
$$


However, this optimal decision for entrepreneurs can never be achieved since the distribution of each venture projects is private information. As a matter of fact, entrepreneurs decide which venture projects to invest from their potential investment opportunities and only depend on their own experience or historical information. In this sense, they can only achieve the suboptimal decisions, and the problem they faced at beginning of each period can be represented as follows:

$$
\max _{\varepsilon_{t}^{k i}, k \in\{w, s\}} \bar{\pi}\left(c_{i}, t\right),
$$

where $\bar{\pi}\left(c_{i}, t\right)$ is represented as the following equation:

$$
\begin{aligned}
\bar{\pi}\left(c_{i}, t\right)= & \sum_{p_{j} \in \mathscr{C}_{t-1}^{i}}\left(\lambda^{i} W_{t-1}^{i}\right) \frac{\left(1+r_{j}\right)}{\left|\mathscr{C}_{t}^{i}\right|}+\left(1-\lambda^{i}\right)(1+r) W_{t-1}^{i} \\
& -\left(\varepsilon_{t}^{w i}\right)^{\alpha}\left(\varepsilon_{t}^{s i}\right)^{1-\alpha} .
\end{aligned}
$$

From optimal problem and suboptimal problem of entrepreneurs, i.e., equations (5) and (6), respectively, the decision bias of entrepreneur $e_{i}$ at each period $t$ can be obtained.

$$
\Delta_{t}^{i}=\left|\underset{\varepsilon_{t}^{k i}, k \in\{w, s\}}{\operatorname{argmax}} \bar{\pi}\left(c_{i}, t\right)-\underset{\varepsilon_{t}^{k i}, k \in\{w, s\}}{\operatorname{argmax}} \pi\left(c_{i}, t\right)\right| .
$$

Besides, the dynamic process of capital for a specific corporation $c_{i}$ can be described as the following equation:

$$
W_{t}^{i}=\bar{\pi}\left(c_{i}, t\right)+W_{t-1}^{i} .
$$

Assumption 4 (A4). Corporate risk is derived from investment failure. In addition, the strong connection network of entrepreneurs can, to an extent, help to spread corporation risk.

Drawing on Pang and Wang [88] and Park [89], we assume financial accident occurring for corporation $c_{i}$ if and only if his capital for investment is less than zero, i.e., $W_{t}^{i}<0$. Further the strong connection social network of entrepreneurs is supposed to be playing a role of risk spreading following the mainstream conclusions of social capital literatures $[90,91]$. Specifically, when the financial accident of corporation $c_{i}$ occurred at period $t$, the entrepreneurs with whom entrepreneur $e_{i}$ strongly connects with at period $t$ may help corporation $c_{i}$ with probability $\beta$ if their own capital at the current period is more than the investment losses of corporation $e_{i}$ at the last period, i.e., the set of entrepreneurs who may choose to help corporation $c_{i}$ when financial accident occurred for $c_{i}$ can be denoted as follows:

$$
\mathscr{D}_{t}^{i}=\frac{\mathscr{L}_{t}^{s i}}{\left\{e_{j} \mid W_{t}^{j}>W_{t-1}^{i}-W_{t}^{i}\right\}} .
$$

Further, we assume the entrepreneurs who decide to help corporation $c_{i}$ fund corporation $c_{i}$ equally, i.e., the corporation $c_{i}$ would be funded $\left(W_{t-1}^{i}-W_{t}^{i}\right) / \beta\left|\mathscr{D}_{t}^{i}\right|$ by entrepreneurs in $\mathscr{D}_{t}^{i}$ with probability $\beta$ when they encountered financial accident. In circumstance of financial crisis of corporation $c_{i}$, we denote the total amount funded by entrepreneurs in strong connection social network as $L_{t}^{i}$. For corporation $c_{i}$ in financial crisis, once all entrepreneurs with whom he connects in his strong connection social network are incapable to fund him, i.e., $\mathscr{D}_{t}^{i}=\varnothing$ or total amount funded by these entrepreneurs cannot cover the deficit of him, i.e., $L_{t}^{i}<W_{t-1}^{i}$, the corporation $c_{i}$ would go to bankruptcy and be taken over in the next period.

Generally, A1 to A4 above form the theoretical framework describes dynamic process of corporations' investment, entrepreneurs' interactions, and emergence and development of corporation risk in this study. At each period, a specific entrepreneur first faces an alternative set including venture projects which are considered to be invested in by him. In addition, the entrepreneur then decides which venture projects from the alternative set his corporation would invest in according to his own historical investment experience and information provided by his weak ties social networks. At end of this period, all the returns of entrepreneur's investments would be realized and consequently change corporate value of this entrepreneur.

In order to analyze influence of the entrepreneurs' social network on corporate risk contagion, we also reaffirm or set up some other variables for convenience's sake. For each corporation $c_{i}$, firstly, we use the degree of centrality, which is proposed by Phillip F. Bonacich [92] and subsequently used widely in various areas of research studies $[61,93]$ to measure the embeddedness of corporation $c_{i}$ in his social network. Specifically, Denoting $\gamma_{t}^{k i}, k \in\{w, s\}$ as the degree of centrality of corporation $c_{i}$ in his social networks, embeddedness of corporation $c_{i}$ in his social networks during time interval $[0, T]$ can be represented as as follows:

$$
\varphi_{T}^{k i}=\frac{\sum_{t=0}^{T} \gamma_{t}^{k i}}{T}
$$

where the first superscript $w$ and $s$ represent weak ties and strong connection, respectively.

Secondly, following various prior studies [94-96], we use survival rate $\chi_{T}$ of corporations during time interval $[0, T]$ to measure the systematical risk of the market and the possibility of expected loss $\phi_{T}^{i}$ to measure corporate individual risk of $c_{i}$ during time interval $[0, T]$. According to A2 and $\mathrm{A} 3, \phi_{T}^{i}$ can be represented as follows:

$$
\phi_{T}^{i}=\frac{0\left[\sum_{t=0}^{T} \int_{-\infty}^{0} 1 / \sqrt{2 \pi} \bar{\sigma}_{t}^{i} \exp \left(-\left(x-\bar{\mu}_{t}^{i}\right)^{2} / 2\left(\bar{\sigma}_{t}^{i}\right)^{2}\right)\right]}{T},
$$

where $\bar{\mu}_{t}^{i}=\left(\sum_{p_{j} \in \mathscr{C}_{t}^{i}} \mu_{j}\right) /\left|\mathscr{C}_{t}^{i}\right|$ and $\left(\bar{\sigma}_{t}^{i}\right)^{2}=\left(\sum_{p_{j} \in \mathscr{C}_{t}^{i}} \sigma_{j}^{2}\right) /\left|\mathscr{C}_{t}^{i}\right|$.

At last, we measure corporate risk contagion as spillover effect of financial accident in social networks drawing on numerous literatures [97-99]. Denoting $\rho_{T}^{i}$ as the period at which corporation $c_{i}$ first suffers financial accident during time interval $[0, T]$, the spillover effect of social networks of corporation $c_{i}$ during time interval $[0, T]$ can be represented as $\omega_{T}^{k i}, k \in\{w, s\}$ by the following equation: 


$$
\omega_{T}^{k i}=\max \left[0, \min _{e_{j} \in \underset{t \in[0, T]}{\mathcal{L}_{t}^{k i}}}\left(\rho_{j}-\rho_{i}\right)\right],
$$

where the first superscript $w$ and $s$ represent weak ties and strong connection, respectively.

\section{Simulation and Analysis}

According to A1 to A4 in Section 3, the process of simulation is shown as Figure 2. In order to simulate dynamics interactions in the market numerically, we use free software called NetLogo5.1.0, which effectively deals with various heterogeneity problems in economics and management $[79,100]$. To initialize system configuration, we assign parameters with the following initial value and randomly generate "small-world" networks, including weak ties and strong connection social networks for entrepreneurs.

$$
N=600,000, m=100,000, \bar{d}=3, \lambda s^{i}=0.8, \alpha=0.7, \beta=0.5 \text {. }
$$

In order to be consistent with the reality, the initial values of parameters we set above in our simulation are based on three specific reasons. First, the data collected from Crunchbase are used to determine the ratio between the number of venture projects and it of investors. Specifically, we track the investment of 100 major investors between January 1, 2015 and January 1, 2020 and calculate the average number of venture projects invested by these investors per year as estimated value of the ratio $m / N$. Second, the values of parameters for influence radius, entrepreneurs' cost function, and corporate risk strategies are fixed according to previous literatures $[5,85,96,101]$. At last, we need to ensure that there are enough agents proxied for venture projects and entrepreneurs in our simulation to depict characteristics of market evolution. It is worth noting that we also fix value of ratio $m / N$ in a wider range, i.e., $[0.05,1.5]$, the value of $\bar{d}$ in $\left\{n \mid n \in N^{+}, n \leq 20\right\}$ and the value of $\alpha$ and $\beta$ in the range of $(0,1)$ to test the robustness of our conclusions. The main results of this study are still unchanged.

In addition, following Katriel [102], the initial capital possessed by corporations $W_{o}^{i}$ is supposed to have an exponential distribution, i.e., $\operatorname{Exp}(\delta)$. If we denote the rate parameter of $W_{o}^{i}$ as $\delta$, we have probability density function for $W_{o}^{i}$ shown as equation (15). In addition, in order to capture the different risk characteristics of venture projects, we assume $\mu_{i}$ and $\sigma_{i}$ subject to uniform distribution $[a, b]$ and $[u, v]$, respectively, based on Yang et al. [79].

$$
f(x, \delta)= \begin{cases}\delta e^{-\delta x}, & x \geq 0, \\ 0, & x<0,\end{cases}
$$

where $\delta=1, a=-0.6, b=0.4, u=0.05$, and $v=0.1$.

At last, for simplifying the configuration, the risk-free rate is supposed as $r=0$, and function $K_{t}^{i}(x), i \in\{w, s\}$ is represented as (16) without loss generality.

$$
K_{t}^{i}(x)=\log _{\zeta_{i}}(x+1),
$$

where $\varsigma_{s}$ and $\varsigma_{w}$ are 3 and 2, respectively.

The diminishing marginal value of entrepreneurs' effort to maintain their social networks and the difference between strong connection and weak ties networks are captured by function $K_{t}^{i}(x)$ in (16). Further, we initialize $\varepsilon_{0}^{s j}$ and $\varepsilon_{0}^{w j}$ as 6 and 15 , respectively.

4.1. Process of Corporate Risk Contagion. The role played by the entrepreneurs' social network in corporate risk contagion is complex. On the one hand, the social networks of entrepreneurs encourage similar investment strategies, which may speed up corporate risk contagion and result in increasing of systemic risk of the market. In addition, on the other hand, social networks provide entrepreneurs more information and promote the experience sharing of individuals and consequently improve investment performance of corporations $[101,103,104]$. In this study, our framework captures the characteristics of these two aspects of social networks and describes heterogeneous interactions among entrepreneurs through social networks.

In order to investigate the influence of social networks on corporate risk contagion, we normalize $\omega_{T}^{k i}$ into $\bar{\omega}_{T}^{k i}$, where $\bar{\omega}_{T}^{k i} \in[0,1]$ and $k \in\{w, s\}$ count the normalized spillover effect for each corporation during time interval $[0, T], T \in\{1,2, \ldots, 1000\}$ and further denote $\mathscr{W}_{T}^{k}, k$ $\in\{w, s\}$ as the proxy for whole risk contagion of social networks, shown as follows:

$$
\mathscr{W}_{T}^{k}=\frac{\sum_{t=0}^{T} W_{t}^{i}}{\sum_{c_{i} \in \mathbb{C}} \sum_{t=0}^{T} W_{t}^{i}} \omega_{T}^{k i} .
$$

It is obvious that the whole risk contagion of social networks is a weighted sum of spillover effect of each corporation from equation (17). Considering dynamic change process of whole risk contagion of social networks, Figure 3(a) illustrates changes of whole risk contagion over iterations of simulation. According to this scatter figure, it shows that the financial accident firstly occurred in strong connection social network. The first financial accident in weak ties social network is delayed approximate 90 iterations compared with it in strong connection social network (approximately in 121 and 211 iterations for strong connection and weak ties social network, respectively). Besides, the process of corporate risk contagion is nonlinear, and the volatilities of corporate risk contagion are gradually decreased over time, no matter in strong connection or weak ties social networks. At last, in equilibrium, corporate risk contagion in strong connection and weak ties social networks is convergent at approximately 0.62 and 0.39 , respectively.

Since whole risk contagions in both strong connection and weak ties social networks are convergent after approximately 700 iterations as shown in Figure 3(a), we count the normalized spillover effect $\bar{\omega}_{T}^{k i}$ and embeddedness in social networks $\varphi_{T}^{k i}$ for each corporations in time interval $[0,700]$. To obtain stable statistical data, every variable we captured during the simulation is mean of a 100 times simulation. The fitting curves shown in Figure 3(b) describe 


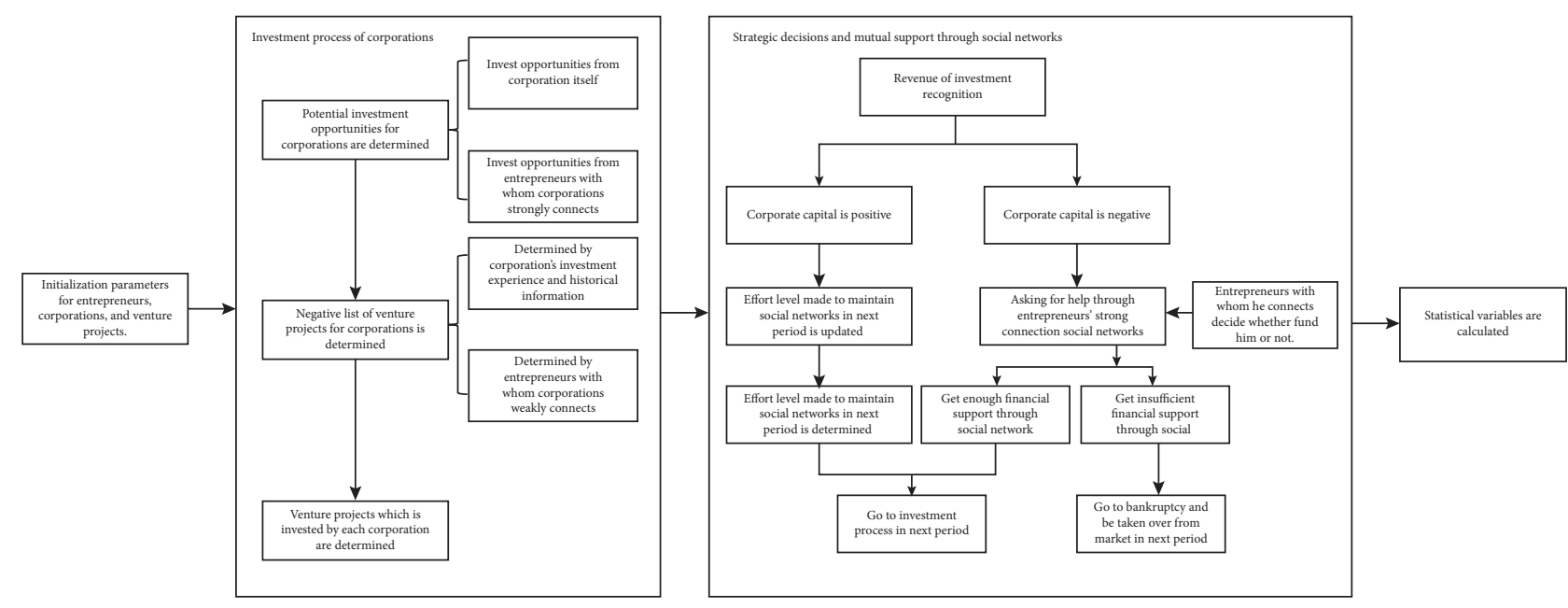

FIGURE 2: Process of simulation.

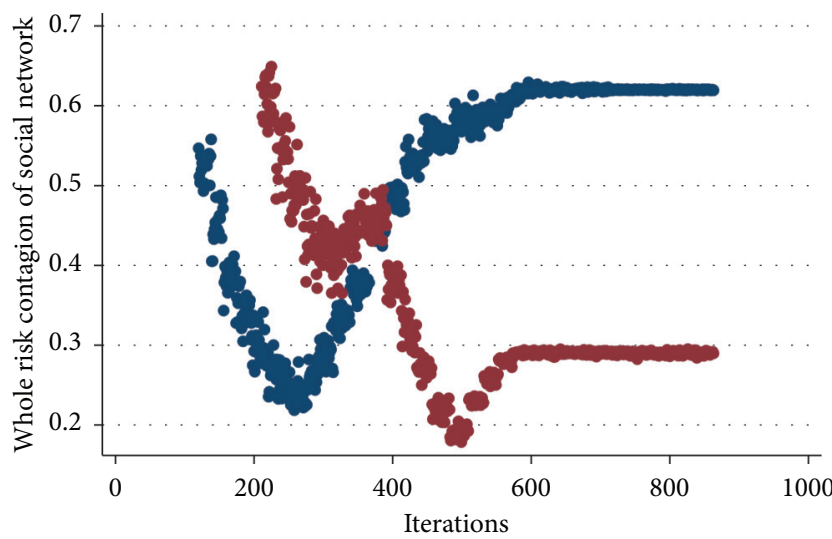

- Strong connections

- Weak ties

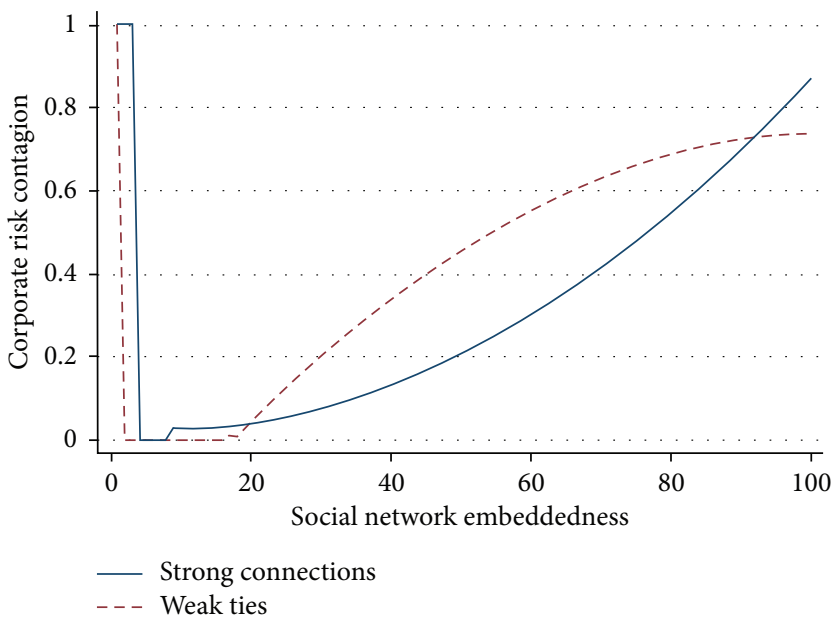

(b)

(a)

FIgURE 3: Social networks and risk contagion process. (a) Whole risk contagion over time. (b) Risk contagion and social network embeddedness.

the relationship between corporate risk contagion and the social network embeddedness of its entrepreneur. According to Figure 3(b), either strong connection social networks or weak ties social networks can positively influence corporate risk contagion. However, it is worth noting that the fitting curve for strong connection networks is convex, while it for weak ties networks is concave. This implies that influence of weak ties of entrepreneurs on corporate risk contagion tends to converge. In addition, on the other hand, the strong connections of entrepreneurs may lead to synchronicity of corporate risk. Generally, from the perspective of risk contagion process, both strong connections and weak ties can significantly improve the corporate risk contagion. In addition, compared with weak ties, the corporate risk contagion is more sensitive to strong connections. This result is consistent with Bryan M. Parsons [105].
4.2. Consequences of Corporate Risk Contagion. According to prior studies [106-108], many scholars have argued that the informal insurance offered by social networks often breeds ambitions and desires of entrepreneurs which lead to vigorous expansionism and low level of cash holdings and eventually results in an increasing of corporate risk. Nevertheless, some other scholars have provided conflict evidence [109-112]. They have shown that entrepreneurs' social networks are seemed as an implicit credit guarantee for their corporations. Those entrepreneurs who occupied the dense position and deeply embedded in social networks are found to be more likely to access to determinant market resource and financial support and consequently bring corporate risk mitigation. In this study, we consider the influence of social networks on consequences of corporate risk contagion with two aspects. First, we focus on how 
social networks affect risk exposure of individual corporations. And then, influence on systematic risk of the whole market is investigated.

If we use possibility of expected loss to measure risk exposure of an individual corporation following assumptions in Section 3.2, Figure 4(a) shows how social networks influence risk exposure of corporations. In Figure 4(a), the abscissa is the social network embeddedness $\varphi_{T}^{k i}$, and the ordinate is the risk exposure which is represented by possibility of expected loss $\phi_{T}^{i}$. Setting time interval $T=700$, the curves in Figure 4(a) illustrate how corporate risk exposure changes with entrepreneurs' social networks. Consistent with the mainstream research conclusions pertaining to social networks and corporate risk-taking [113, 114], entrepreneurs are inspired to take a radical capital allocation by their weak ties and then results in a high risk exposure of their corporations. The dash curve in Figure 4(a) depicts the monotonous relationship between corporate risk exposure and weak ties embeddedness. However, this monotonous relationship no longer holds in strong connection networks. The almost inverted U-shaped solid curve in Figure 4(a) shows that an extreme risk exposure can be reached when strong connections embeddedness takes values within range approximately in $[35,40]$. This result may be induced by the balance of three effects brought by strong connections. The first effect is the optimizing effect of strong connections, which help entrepreneurs to access to venture projects with high quality venture projects and can significantly decrease the risk exposure of corporations. The second one is incentive effect of strong connections for entrepreneurs. This effect derived from overconfident expectations for benefits brought by social networks and leads to excessive investment in social networks and risk exposure increasing. In addition, the last one is the risk-sharing effect of strong connection. Deeply embeddedness of strong connections may bring entrepreneurs more financial support when they suffer financial accident. This informal insurance can also help to decrease the risk exposure of corporation. For a specific entrepreneur with limited social capital, incentive effect is the main driver behind entrepreneurs' decision-making. Therefore, corporate risk exposure increases with the strong connections. However, for entrepreneurs who deeply embedded in strong connections, the informal insurance becomes the determinant of strong connections and thereby decreases their corporate risk exposure. The conclusions derived from Figure 4(a) not only provide alternative evidence for previous studies but also, to an extent, explain the conflict results of scholars.

Further, we consider how social networks influence on systematic risk of the whole market. Denoting $\psi_{T}^{k}$ as weighted sum of social networks embeddedness of corporations, shown as (18), it measures the tightness of social networks of the whole market. In addition, superscripts represent weak ties and strong connections, respectively.

$$
\psi_{T}^{k}=\frac{\sum_{t=0}^{T} W_{t}^{i}}{\sum_{c_{i} \in \mathbb{C}} \sum_{t=0}^{T} W_{t}^{i}} \varphi_{T}^{k i},
$$

where $k \in\{w, s\}$ and $\mathbf{C}_{\mathbf{i}} \in \mathbb{C}$.
If we measure the systematical risk of the whole market with survival rate $\chi_{T}$ as mentioned in Section 3.2, Figure 4(b) describes how social networks influence on systematical risk of the market. According to the solid curve in Figure 4(b), it shows clearly that the strong connections can help to improve the resist capability of systematical risk of the market. However, for weak ties, shown as the dash curve in Figure 4(b), the influence on systematical risk is fluctuating and obscure. The reasons behind this phenomenon are probably caused by the uneven information qualities spreading through weak ties networks. Generally, from the perspective of risk contagion consequences, weak ties network leads entrepreneurs display relative higher level of risk exposure, and strong connection network can help to decrease the systematical risk of the whole market.

4.3. Risk Preference and Corporate Risk Contagion. Since numerous of literatures have argued that the risk contagion is sensitive to risk preference or risk attitude of the decision maker $[98,115,116]$, we consider how risk preference or risk attitude of entrepreneurs moderates the influence of social networks on corporate risk contagion. According to our discussion in Section 4.1, we conclude that both strong connections and weak ties can significantly improve the corporate risk contagion. However, this result is built on the hypothesis that all entrepreneurs in the market have same risk preference or risk attitude, i.e., $\lambda^{i}=\lambda^{j}=0.8, i, j \in$ $\{1, \ldots, N\}$. In order to verify the influence of entrepreneurs' risk preference, we randomly select 200,000 entrepreneurs to form a group, which represents entrepreneurs with high (middle or low) risk preference, denoting as $\mathbb{E}_{H}\left(\mathbb{E}_{M}\right.$ or $\left.\mathbb{E}_{L}\right)$. It is obvious that the following relationship exists: $\mathbb{E}_{H} \cup \mathbb{E}_{M} \cup \mathbb{E}_{L}=\mathbb{E}, \mathbb{E}_{i} \cap \mathbb{E}_{j}=\varnothing, i, j \in\{H, M, L\}$, and $\left|\mathbb{E}_{i}\right|=$ $200,000, i \in\{H, M, L\}$. Then, for each set of entrepreneurs $\mathbb{E}_{H}, \mathbb{E}_{M}$, and $\mathbb{E}_{L}$, the parameter of risk preference $\lambda^{i}$ is initialized as $\lambda_{H}^{i}=0.9, \lambda_{M}^{i}=0.6$, and $\lambda_{L}^{i}=0.2$, respectively. Consistent with previous sections, setting time interval $T=700$. The Figure 5 illustrates how entrepreneurs' risk preference moderates the influence of social networks on corporate risk contagion.

Figures 5(a) and 5(b) show the role of entrepreneurs' risk preference in influence of social networks of strong connections and weak ties, respectively. Generally, the conclusions derived from Figure 5 firstly verify the results of Section 4.1 and then depict that the risk preference of entrepreneurs positively moderates the influence on corporate risk contagion of strong connections but not sensitive to the influence of weak ties.

\section{Model Extension}

In Section 3 and Section 4, a framework is proposed to describe heterogeneous behaviors of entrepreneurs microcosmically. Thus, the important characteristics of influence of social networks on corporate risk contagion can be captured by simulation. However, this framework has two notable limitations. One limitation is the exogenous assumption for risk management strategies of corporations, 


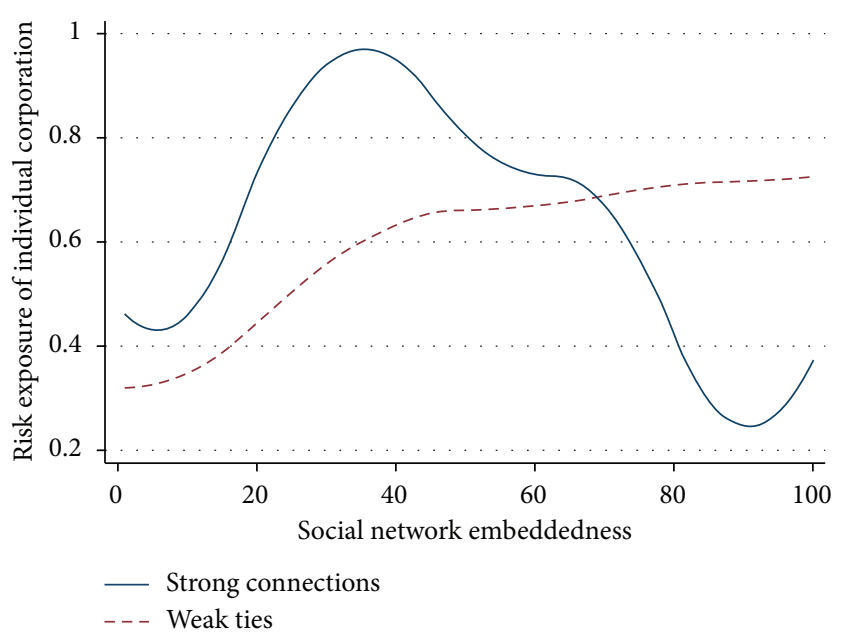

(a)

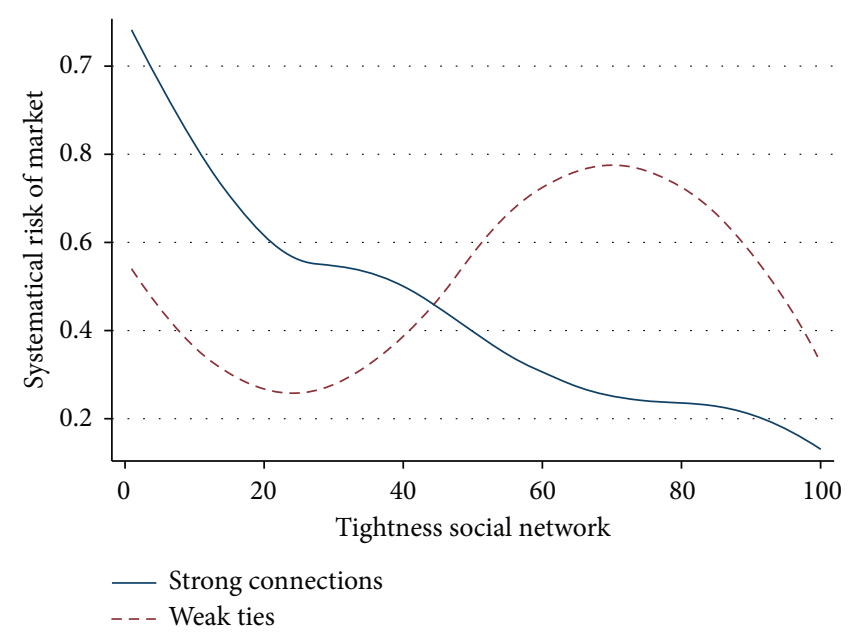

(b)

FIGURE 4: Social networks and risk contagion consequences. (a) Risk exposure of individual corporation. (b) Systematical risk of market.

and the other limitation is the homogeneous assumption for corporate scales. In this section, the framework is extended through relaxing these two assumptions, and a new dynamic equilibrium is discussed by reconducting the simulations.

5.1. Endogenous Risk Management Strategies. The exogenous assumption for risk management strategies is mainly embodied in A2. In this assumption, we assume that the proportion of cash invested in venture projects is a fixed value for all corporations, i.e., $\lambda^{i}=\lambda^{j}, i, j \in\{1, \ldots, N\}$. Even when we discuss moderated effect of entrepreneurs' risk preferences, we just fixed three different values for entrepreneurs with different risk preferences for simplified and shielded from endogenous of risk management strategies of different corporations. However, the risk management strategies of corporations can be seemed as a dynamic process in reality. Corporations may dynamically adjust the risk management strategies to improve their investment performance. Therefore, we relax the exogenous assumption for risk management strategies and make risk management strategies decided by corporations endogenously at each time period. Different from optimal problem (6), the optimal problem of entrepreneurs in this case can be re-represented as follows:

$$
\max _{\lambda_{t}^{i}, \varepsilon_{t}^{k, k}, k \in\{w, s\}} \bar{\pi}\left(c_{i}, t\right),
$$

where $\lambda_{t}^{i}$ measures risk management strategies decided by corporation $c_{i}$ at time period $t$.

In addition, we initialize risk management strategies at the beginning of simulation $\lambda_{0}^{i}$ as a random variable which subject to uniform distribution $(0,1)$ without losing generality. Consistent with previous sections, in order to obtain stable and convergent conclusions, the iteration of simulation is set to $T=700$, and the statistical variables we captured during simulation are a mean value of a 100 times simulation. At each period $t$ in time interval $[0, T]$, we first identify the entrepreneurs with a fixed degree of centrality $z, z \in\{1, \ldots, 100\}$. And then, the one-period lag mean value in whole time interval $[0, T]$ of risk management strategies of corporations whose corresponding entrepreneurs positioned in the fixed degree of centrality $z$ is calculated as $\Gamma_{z}^{k}, k \in\{w, s\}$ using the following equation:

$$
\Gamma_{z}^{k}=\frac{\sum_{t=t_{0}}^{T-1} \sum_{e_{i \in \mathbb{E}_{t}^{\mathbb{E}}}} \lambda_{t+1}^{i}}{\left(T\left|\mathbb{E}_{t}^{z}\right|\right)},
$$

where $\mathbb{E}_{t}^{z}=\left\{e_{i} \mid \gamma_{t}^{k i}=z\right\}, t_{0}$ is initialized as 400 to keep clear of no convergence in early periods and $k \in\{w, s\}$ represents weak ties and strong connections, respectively.

Pairing degree of centrality at period $t$ and one-period lag mean value of risk management strategies calculated in period $t+1$ in time interval $[0, T]$, Figure 6(a) shows how social networks influence on corporations' risk management strategies. In Figure 6(a), the abscissa represents the degree of centrality $z, z \in\{1, \ldots, 100\}$, and the ordinate represents corresponding mean value of risk management strategies of corporations. From this figure, we ascertain that weak ties can motivate entrepreneurs intend to adopt more riskier strategies. This is the result of the role played by weak ties in corporate investment process and is equivalent to a kind of downside risk control strategies. However, for strong connections, things become more complex. The fluctuating solid curve in Figure 6(a) captures dynamic change process of risk management strategies. It shows that for entrepreneurs, as the expansion of accessible venture projects brought by their strong connections, entrepreneurs may continuously adjust their risk management strategies to optimize their investment performance.

5.2. Heterogeneous Corporate Scale. There are many studies especially those in area of Enterprise Lifecycle Management (ELM) have often argued that the role of social networks is very different for corporations in different stages [117-119]. However, this difference of corporations is not captured by the framework proposed above. In this section, we consider 


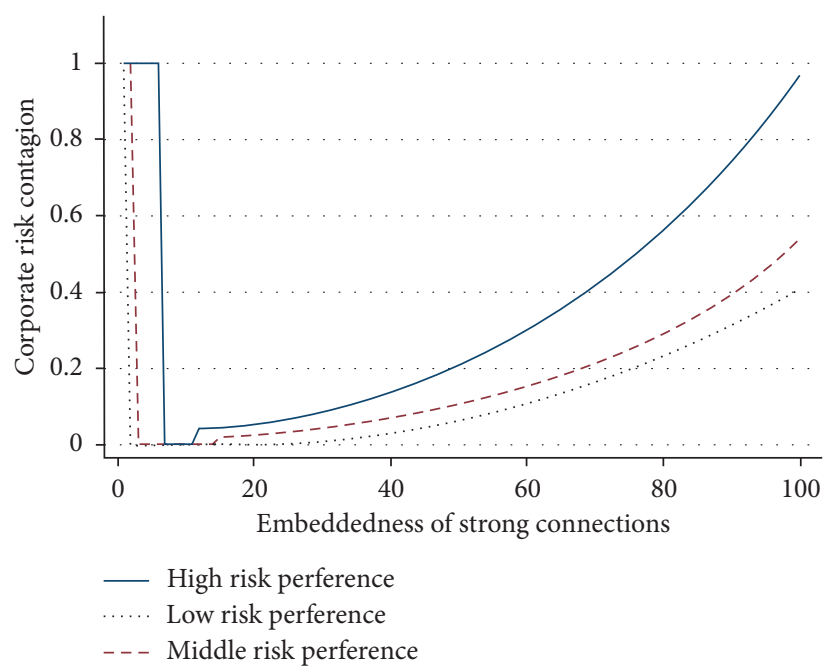

(a)

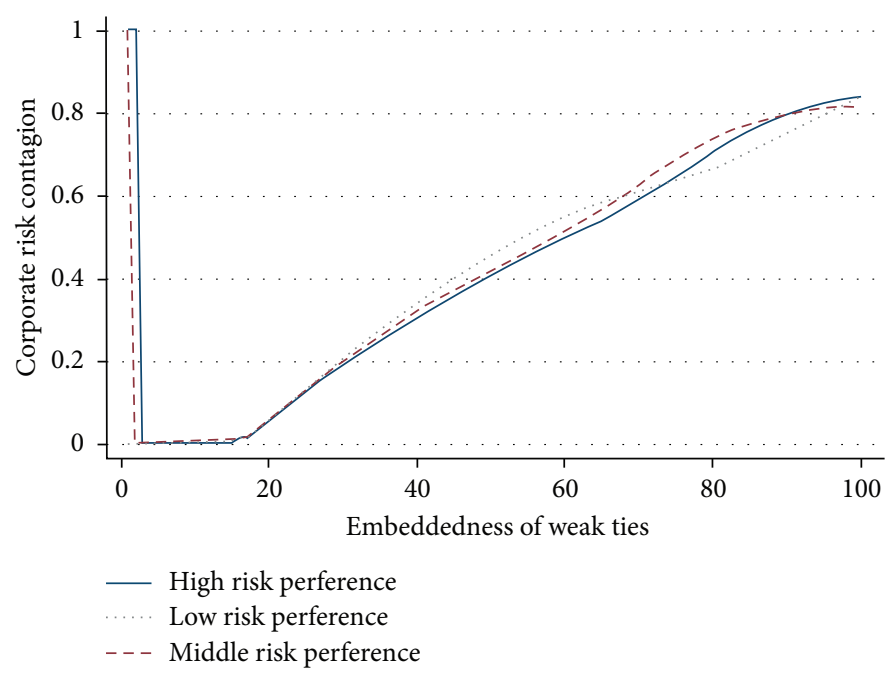

(b)

FIGURE 5: Risk preferences and risk contagion process. (a) Strong connection networks. (b) Weak ties networks.

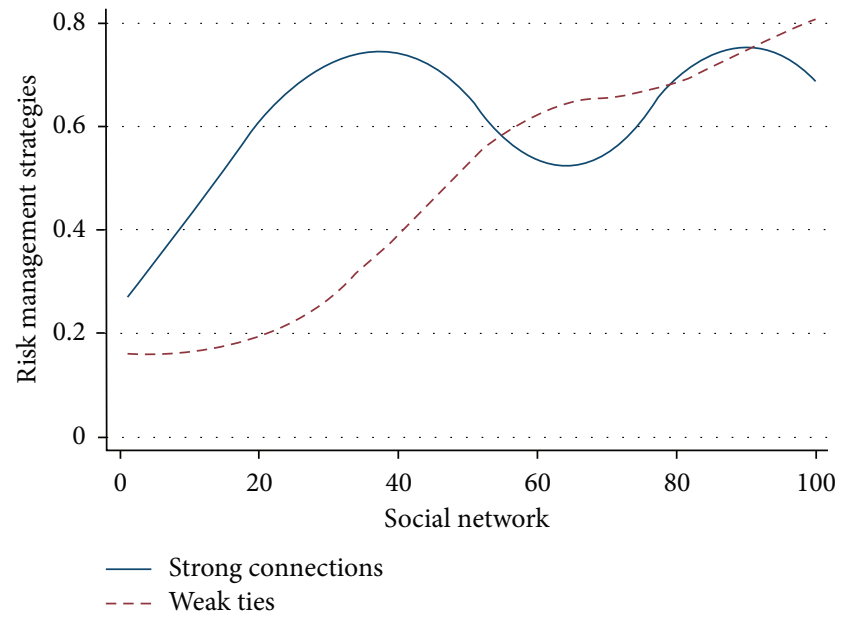

(a)

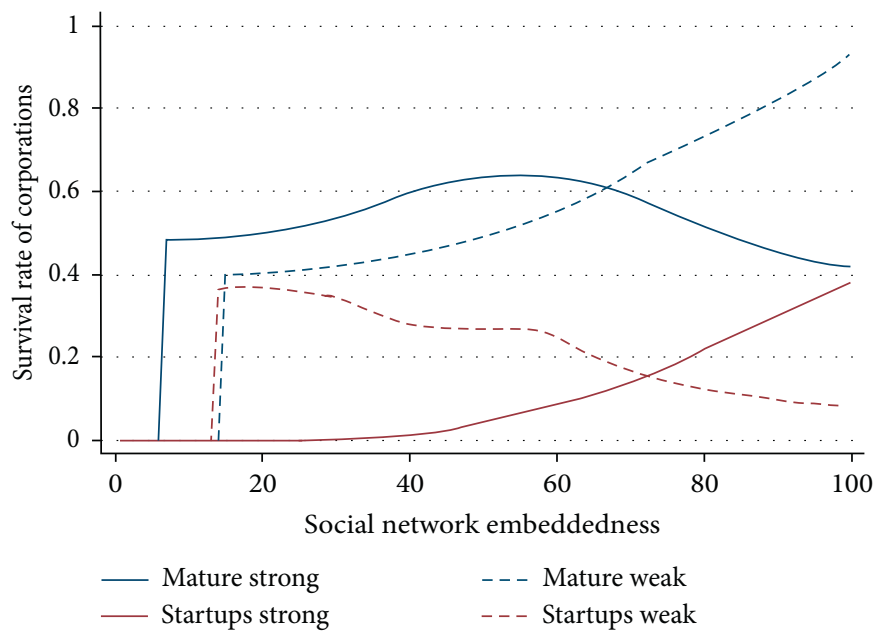

(b)

Figure 6: Simulation analysis of the extended model. (a) Social networks and risk management strategies. (b) Social networks and corporate scale.

to describe corporations in different stages in terms of corporate scale from two aspects. First, compared with startups, mature corporations possess much more capital that can be used in investment. In addition, there are more venture projects accessible for mature corporations than small and middle corporations. In order to capture these characteristics, all the corporations in the market are firstly classified into three categories: established corporations, middle corporations, and startups according to their initial capital $W_{o}^{i}$. For each specific corporation $c_{i}$, if its initial capital $W_{o}^{i} \in(0,1]$ after system configuration, it is seemed as a startup; if its initial capital $W_{o}^{i} \in(1,2]$ after system configuration, it is seemed as a middle corporation; and if its initial capital $W_{o}^{i} \in(2,+\infty)$ after system configuration, it is seemed as a mature corporations. We then make the influence radius of venture projects initialized differ in these three categories of corporations. Specifically, we initialize $\bar{d}$ as 2, 5, and 7 for startups, middle corporations, and mature corporations, respectively.

Table 2 reports general index of startups, middle corporations, and mature corporations. According to Table 2, first we find the numbers of these three types of corporations constitute the pyramid structure of the market, which is highly in line with the reality. Second, Table 2 illustrates that the mature corporations possess much larger capital and can access to more resource brought by both strong connections and weak ties on average compared with startups. This reflects great resource accumulation of corporate empires. Besides, contrary to startups, mature corporations operate more stable. They can not only access to high quality venture projects but also obtain more financial support when they suffered financial accident. This explains why survival rate of 
Table 2: General index of startups, middle corporations, and mature corporations.

\begin{tabular}{|c|c|c|c|c|c|c|c|}
\hline & Numbers & $\begin{array}{l}\text { Mean } \\
\text { scale }\end{array}$ & $\begin{array}{l}\text { Max. strong } \\
\text { connections }\end{array}$ & $\begin{array}{l}\text { Max. weak } \\
\text { ties }\end{array}$ & $\begin{array}{c}\text { Time of first } \\
\text { financial accident }\end{array}$ & $\begin{array}{c}\text { Time of survival rate } \\
\text { convergence }\end{array}$ & $\begin{array}{l}\text { Mean survival } \\
\text { rate }(\%)\end{array}$ \\
\hline Startups & 315,000 & 0.458 & 19 & 48 & 64 & 722 & 29.1 \\
\hline $\begin{array}{l}\text { Middle } \\
\text { corporations }\end{array}$ & 189,000 & 1.248 & 27 & 39 & 179 & 539 & 41.2 \\
\hline $\begin{array}{l}\text { Mature } \\
\text { corporations }\end{array}$ & 96,000 & 2.314 & 69 & 92 & 322 & 397 & 74.5 \\
\hline
\end{tabular}

mature corporations in equilibrium is much higher than it of startups.

Further, for each type of corporations, we investigate the relationship of social networks and corporate success. According to Table 2, we conduct 800 iterations of simulation to obtain stable results. Figure 6(b) illustrates the influence of social networks on corporate success. In Figure 6(b), the navy curves describe the influence of social networks for mature corporations, while the maroon curves describe the influence of social networks for startups. According to this figure, weak ties can significantly decrease the corporate risk of mature corporations. However, the contribution of strong connections for mature corporations is nonlinear. The reason behind this phenomenon is the downside risk control brought by weak ties is more important for mature corporations since the alternative venture project for mature corporations is enough. However, for startups, the conclusions are almost contrary. Our simulation shows that strong connections are more valuable for startups to manage their corporate risk. In addition, inconsistent with our expectation, strong connections even induce an upward trend of risk of startups. This conclusion predicts that minority of strong connections play a decisive role for startups' business success. In addition, it is not necessary for startups to cost much to maintain their extensive weak ties. Generally, our extended simulation illustrates that weak ties are important for business success of mature corporations. However, for startups, the strong connections are more valuable to maintain. These conclusions can be seemed as a support for results founded by Dahl and Sorenson [120].

\section{Conclusions and Discussion}

The social networks of entrepreneurs provide an alternative possible path for corporate risk contagions. Most of prior studies on the determinants of corporate risk contagion documented several financial factors that influence corporate strategies. In addition, limited literatures which discussed influence of nonfinancial factors, such as social networks, only seemed corporate risk as a fixed static state and did not dynamically consider the consequence and process of corporate risk contagion. In this study, we propose a framework that incorporates interaction social networks structure including strong connections and weak ties, decision-making process of entrepreneurs, and various investment opportunities or venture projects for corporations as a mean to describe interactions of entrepreneurs through their social networks. This systematical framework not only takes into account heterogeneity of entrepreneurs, corporations, and venture projects but also captures important characteristics of interaction of entrepreneurs, such as information sharing and coinvestment.

The numerical simulations of our framework show several notable findings. First, from the perspective of risk contagion process, either strong connections or weak ties of social networks can enhance density of corporate risk contagion. In addition, compared with weak ties, corporate risk contagion is more sensitive to strong connections. Second, from the perspective of risk contagion consequences, strong connections and weak ties of social networks play very different role in influencing risk of individual corporations and systematical risk of the market. Weak ties can significantly improve risk exposure of individual corporations, while strong connections may probably decrease the systematical risk of the whole market. In addition, the moderated effect of entrepreneurs' risk preference or attitude is partly verified. The influence of strong connections can be positively moderated by risk attitude of entrepreneurs. However, it of weak ties is not sensitive. At last, we extend our framework in two specific circumstances to make it more realistic. In first circumstance, we make corporate risk strategies endogenous and assume that entrepreneurs can dynamically adjust their risk strategies to optimize their investment performance. The extended framework indicates that the larger an entrepreneur's weak ties of relation, more riskier strategies adopted by entrepreneurs. In second circumstance, we distinguish between mature corporations and startups. The simulation analysis for this extended framework shows that weak ties of entrepreneurs are more important for mature corporations to achieve business success compared with strong connections. On contrary, for startups, strong connections are more valuable for their entrepreneurs to maintain.

Our results make important theoretical contributions to social capital literatures. This study is among the first to address influence of social networks on corporate risk from the complex systematical perspective. Compared with the approaches taken in other studies, the simulation approach we proposed is more comprehensive and systematical and can be used to explain either macroscopic or microscopic influence of social networks. Apart from the convenience of multiagent simulation, this framework is not limited to analyze the influence of structure of social networks and the optimal strategies of a specific entrepreneur or corporation and is easy to extend to a variety of complex circumstances. The main results of our numerical simulations also contribute to previous literatures. First, our simulation results 
are consistent with analysis of Bryan M. Parsons [105] who argued that the risk contagion is more sensitive to strong connections compared with weak ties and empirical evidence from Dahl and Sorenson [120] that weak ties are important for mature corporations to achieve business success, but for startups, strong connections are more determinant for their development. Then, our results not only support some widely accepted economic phenomena theoretically but also, to an extent, provide an alternative explanation for conflicting conclusions derived from prior studies pertaining to whether the social networks of entrepreneurs increase or decrease corporate risk. Lastly, the moderated effect of entrepreneur's risk attitude and different influence of strong connections and weak ties from corporate lifecycle perspective, which are little discussed in prior literatures, are analyzed in our study.

The findings of this study also provide useful practical implications and management insights for corporations. First, discrimination of information that derived from weak ties of entrepreneurs is crucial for corporations because redundant and inaccurate information from weak ties may result in riskier investment strategies and consequently increase corporate risk contagion and risk exposure of individual corporations. Then, corporations should be alert to uncertain of venture projects that brought by entrepreneurs' strong connections, especially when their entrepreneurs are risk preference. Third, since social networks play very different roles in corporate lifecycle, the entrepreneurs are encouraged to adjust the investment in their social capital dynamically to achieve business success. At last, we suggest that entrepreneurs should optimize the combination of their strong connections and weak ties. An appropriate structure of social networks cannot only decrease corporate risk contagion and exposure but also improve performance of corporate investment. For regulatory authorities, we argue that it can significantly decrease systematical risk of the market to encourage the coinvestment model and improve information transparency. Because of nonlinear relationship between strong connections and risk exposure of individual corporations and important role of strong connections for startups, we ascertain that a new partner assistance model copied from the targeted poverty alleviation model from Chinese government may help small- and medium-size corporations grow and better plug into larger market. In addition, for financial institutions, the informal insurance of entrepreneurs' strong connections is verified through sharing effect according to our findings. However, we remind that this informal insurance can be weakened because of incentive effect, especially when entrepreneurs are overconfident.

One limitation of this study is that we assume entrepreneurs to be perfectly rational when they make decisions. In reality, the capacity of entrepreneurs to process information is limited. Thus, although our assumption of perfect rationality simplifies our framework, it may also affect some of our conclusions. Moreover, although our study considers different functions and costs of strong connections and weak ties, we omit the mutual conversions of these two types of social networks. Adding the conversion process into our framework could produce more reliable and interesting conclusions. Finally, although most of the parameters in our simulation are derived from previous literatures, the framework proposed in this study still needs to be validated by empirical evidence. In addition, more empirical examination for this framework would be conducted in our future research.

\section{Data Availability}

The data used to support the findings of this study are included within the article.

\section{Conflicts of Interest}

The authors declare that they have no conflicts of interest.

\section{Acknowledgments}

This study was supported by National Natural Science Foundation of China (grant number: 71701166), Social Science Planning Project of Sichuan Province of China (grant number: SC19B004), and Central University Basic Scientific Research Business Expenses Special Funds (grant number: JBK2004006).

\section{References}

[1] J. B. Doornich, "Managerial learning from social capital during internationalization," International Business Review, vol. 27 , no. 4, pp. 877-892, 2018.

[2] R. Abdulahad, K. Brownlee, J. R. Graham, and W. J. Montelpare, "Measuring social capital: an adaptation and translation into Arabic of the onyx and bullen social capital scale for Iraqi-Canadians," Australian Social Work, vol. 71, no. 4, pp. 462-477, 2018.

[3] V. Zheng and S.-L. Wong, "The mystery of capital: eurasian entrepreneurs' socio-cultural strategies for commercial success in early 20th-century Hong Kong," Asian Studies Review, vol. 34, no. 4, pp. 467-487, 2010.

[4] M. Fornoni, F. Mas-Verdú, D. Soriano, and S. Dobón, "Universidad social capital and the competitiveness of entrepreneurs: A review of the literature and proposals," Entrepreneurship and Business, Springer, Berlin, Germany, pp. 247-268, 2009.

[5] B. Batjargal and M. Liu, "Entrepreneurs' access to private equity in China: the role of social capital," Organization Science, vol. 15, no. 2, pp. 159-172, 2004.

[6] T.-C. Chou, J.-R. Chen, and S. L. Pan, "The impacts of social capital on information technology outsourcing decisions: a case study of a Taiwanese high-tech firm," International Journal of Information Management, vol. 26, no. 3, pp. 249-256, 2006.

[7] B. Buechel, T. Hellmann, and M. M. Pichler, "The dynamics of continuous cultural traits in social networks," Journal of Economic Theory, vol. 154, pp. 274-309, 2014.

[8] S. C. Buskirk, "Social networks: mechanisms for building academic entrepreneurs' social cap...: EBSCOhost," Journal of Entrepreneurship \& Management, vol. 6, no. 3, pp. 1-16, 2017.

[9] S. P. Ferris, D. Javakhadze, and T. Rajkovic, "CEO social capital, risk-taking and corporate policies," Journal of Corporate Finance, vol. 47, pp. 46-71, 2017. 
[10] E. Hartmann and S. Herb, "Opportunism risk in service triads-a social capital perspective," International Journal of Physical Distribution \& Logistics Management, vol. 44, no. 3, pp. 242-256, 2014.

[11] K.-C. Ho, H.-P. Yen, Y. Gu, and L. Shi, "Does societal trust make firms more trustworthy?" Emerging Markets Review, vol. 42, p. 100674, 2020.

[12] P. Dubini and H. Aldrich, "Personal and extended networks are central to the entrepreneurial process," Journal of Business Venturing, vol. 6, no. 5, pp. 305-313, 1991.

[13] X. Neumeyer, S. C. Santos, A. Caetano, and P. Kalbfleisch, "Entrepreneurship ecosystems and women entrepreneurs: a social capital and network approach," Small Business Economics, vol. 53, no. 2, pp. 475-489, 2018.

[14] L. Renneboog and Y. Zhao, "Director networks, turnover, and appointments," European Financial Management, vol. 26, no. 1, pp. 44-76, 2019.

[15] M. S. Granovetter, "The strength of weak ties," American Journal of Sociology, vol. 78, no. 6, pp. 1360-1380, 1973.

[16] S. Benlabsir, "Knowledge management and social capital: a literature review," in Proceedings of the International Conference on Intellectual Capital, Knowledge Management \& Organizational Learning, pp. 341-347, Toronto, Canada, December 2016.

[17] E. O. Laumann, J. Galaskiewicz, and P. V. Marsden, "Community structure as interorganizational linkages," Annual Review of Sociology, vol. 4, no. 1, pp. 455-484, 1978.

[18] G. Hilary and K. W. Hui, "Does religion matter in corporate decision making in America?," Journal of Financial Economics, vol. 93, no. 3, pp. 455-473, 2009.

[19] L. Postelnicu and N. Hermes, "The economic value of social capital," International Journal of Social Economics, vol. 45, no. 6, pp. 870-887, 2018.

[20] I. Hasan, C.-K. Hoi, and Q. Wu, "Is social capital associated with corporate innovation? Evidence from publicly listed firms in the U.S," Journal of Corporate Finance, vol. 62, Article ID 101623, 2020.

[21] A. Jha, C. J. Boudreaux, and V. Banerjee, "Political leanings and social capital," Journal of Behavioral and Experimental Economics, vol. 72, pp. 95-105, 2018.

[22] G. A. Akerlof, "The missing motivation in macroeconomics," American Economic Review, vol. 97, no. 1, pp. 5-36, 2007.

[23] Y. Grinshtain and A. Addi-Raccah, "Domains of decisionmaking and forms of capital among men and women teachers," International Journal of Educational Management, vol. 34, no. 6, pp. 1021-1034, 2020.

[24] S. Hartlieb, T. R. Loy, and B. Eierle, "Does community social capital affect asymmetric cost behaviour?" Management Accounting Research, vol. 46, Article ID 100640, 2020.

[25] S. Lee, "Shared capitalism, social capital, and intra-organizational dynamics," Journal of Participation and Employee Ownership, vol. 1, no. 23, pp. 144-161, 2018.

[26] M. Polyviou, K. L. Croxton, and A. M. Knemeyer, "Resilience of medium-sized firms to supply chain disruptions: the role of internal social capital," International Journal of Operations \& Production Management, vol. 40, no. 1, pp. 68-91, 2019.

[27] K. Fogel, T. Jandik, and W. R. McCumber, "CFO social capital and private debt," Journal of Corporate Finance, vol. 52, pp. 28-52, 2018.

[28] M. Kannadhasan, P. Charan, P. Singh, and N. Sivasankaran, "Relationships among social capital, self-efficacy, and new venture creations," Management Decision, vol. 56, no. 1, pp. 204-218, 2018.
[29] J. Nahapiet and S. Ghoshal, "Social capital, intellectual capital and the creation of value in firms," Academy of Management Proceedings, vol. 1997, no. 1, pp. 35-39, 1997.

[30] B.-X. Hsu and Y.-M. Chen, "Industrial policy, social capital, human capital, and firm-level competitive advantage," International Entrepreneurship and Management Journal, vol. 15, no. 3, pp. 883-903, 2019.

[31] S. Kang and Y. Na, "The effect of the relationship characteristics and social capital of the sharing economy business on the social network, relationship competitive advantage, and continuance commitment," Sustainability, vol. 10, no. 7, p. 2203, 2018.

[32] J. Novak and P. Bilinski, "Social stigma and executive compensation," Journal of Banking \& Finance, vol. 96, pp. 169-184, 2018.

[33] W. Gao, L. Ng, and Q. Wang, "Does corporate headquarters location matter for firm capital structure?" Financial Management, vol. 40, no. 1, pp. 113-138, 2011.

[34] F. Bloch, G. Genicot, and D. Ray, "Informal insurance in social networks," Journal of Economic Theory, vol. 143, no. 1, pp. 36-58, 2008.

[35] G. Genicot and D. Ray, Informal Insurance, Enforcement Constraints, and Group Formation, Cambridge University Press, Cambridge, UK, 2005.

[36] D. J. Brass and M. E. Burkhardt, "Potential power and power use: an investigation of structure and behavior," Academy of Management Journal, vol. 36, no. 3, pp. 441-470, 1993.

[37] D. Keltner, D. H. Gruenfeld, and C. Anderson, "Power, approach, and inhibition," Psychological Review, vol. 110, no. 2, pp. 265-284, 2003.

[38] C. K. Hoi, Q. Wu, and H. Zhang, "Does social capital mitigate agency problems? evidence from chief executive officer (CEO) compensation," Journal of Financial Economics, vol. 133, no. 2, pp. 498-519, 2019.

[39] D. Hirshleifer and A. V. Thakor, "Managerial conservatism, project choice, and debt," Review of Financial Studies, vol. 5, no. 3, pp. 437-470, 1992.

[40] J. Schneider, Social Capital and Welfare Reform, Columbia University Press, New York, NY, USA, 2006.

[41] R. M. Stulz, "The limits of financial globalization," The Journal of Finance, vol. 60, no. 4, pp. 1595-1638, 2005.

[42] Z. Niu and C. Chen, "Social capital of directors and corporate governance: a social network analysis," Brooklyn Journal of Corporate, Financial \& Commercial Law, vol. 11, no. 2, pp. 343-376, 2017.

[43] D. Acemoglu and F. Zilibotti, "Was prometheus unbound by chance? risk, diversification, and growth," Journal of Political Economy, vol. 105, no. 4, pp. 709-751, 1997.

[44] D. Javakhadze, S. P. Ferris, and D. W. French, "Managerial social capital and financial development: a cross-country analysis," Financial Review, vol. 51, no. 1, pp. 37-68, 2016.

[45] M. Giannetti and Y. Yafeh, "Do cultural differences between contracting parties matter? evidence from syndicated bank loans," Management Science, vol. 58, no. 2, pp. 365-383, 2012.

[46] K. John, L. Litov, and B. Yeung, "Corporate governance and risk-taking," The Journal of Finance, vol. 63, no. 4, pp. 1679-1728, 2008.

[47] Ó. Villarón-Peramato, J. Martínez-Ferrero, and I.-M. García-Sánchez, "CSR as entrenchment strategy and capital structure: corporate governance and investor protection as complementary and substitutive factors," Review of Managerial Science, vol. 12, no. 1, pp. 27-64, 2016. 
[48] A. Jha and Y. Chen, "Audit fees and social capital," The Accounting Review, vol. 90, no. 2, pp. 611-639, 2014.

[49] R. Porta, F. Lopez-de-Silane, A. Shleifer, and R. vishny, "Trust in large organizations," American Economic Review, vol. 87, no. 2, pp. 333-338, 1997.

[50] N. Seth and L. Panda, "Financial contagion: review of empirical literature," Qualitative Research in Financial Markets, vol. 10, no. 1, pp. 15-70, 2018.

[51] D. J. Lucas, "Default correlation and credit analysis," The Journal of Fixed Income, vol. 4, no. 4, pp. 76-87, 1995.

[52] H. Gersbach and A. Lipponer, "Firm defaults and the correlation effect," European Financial Management, vol. 9, no. 3, pp. 361-378, 2003.

[53] M. Davis and V. Lo, "Modelling default correlation in bond portfolios," Risk Analysis, vol. 1, no. 2, pp. 141-151, 2001.

[54] C.-C. Chen, S.-D. Shyu, and C.-Y. Yang, "Counterparty effects on capital structure decision in incomplete market," Economic Modelling, vol. 28, no. 5, pp. 2181-2189, 2011.

[55] R. A. Jarrow and F. Yu, "Counterparty risk and the pricing of defaultable securities," The Journal of Finance, vol. 56, no. 5, pp. 1765-1799, 2001.

[56] J. Cai, F. Eidam, A. Saunders, and S. Steffen, "Syndication, interconnectedness, and systemic risk," Journal of Financial Stability, vol. 34, pp. 105-120, 2018.

[57] C. Zhou, "An analysis of default correlations and multiple defaults," Review of Financial Studies, vol. 14, no. 2, pp. 555-576, 2001.

[58] F. Yu, H. C. F. K. Giesecke, and I. Hawkins, "Correlated defaults in reduced-form models," Journal of Investment Management, vol. 14, no. 2, pp. 33-42, 2005.

[59] X. Jin and F. Nadal De Simone, "A framework for tracking changes in the intensity of investment funds' systemic risk," Journal of Empirical Finance, vol. 29, pp. 343-368, 2014.

[60] S. H. Kang and S. M. Yoon, "Dynamic correlation and volatility spillovers across Chinese stock and commodity futures markets," International Journal of Finance \& Economics, vol. 25, no. 2, pp. 261-273, 2020.

[61] D. Cao, H. Li, G. Wang, X. Luo, and D. Tan, "Relationship network structure and organizational competitiveness: evidence from BIM implementation practices in the construction Industry," Journal of Management in Engineering, vol. 34, no. 3, pp. 1-12, 2018.

[62] K. J. Forbes and R. Rigobon, "No contagion, only interdependence: measuring stock market comovements," The Journal of Finance, vol. 57, no. 5, pp. 2223-2261, 2002.

[63] R. T. Clemen and T. Reilly, "Correlations and copulas for decision and risk analysis," Management Science, vol. 45, no. 2, pp. 208-224, 1999.

[64] M. Segnon and M. Trede, "Forecasting market risk of portfolios: copula-Markov switching multifractal approach," European Journal of Finance, vol. 24, no. 14, pp. 1123-1143, 2018.

[65] Y. Xiao, "The risk spillovers from the Chinese stock market to major East Asian stock markets: a MSGARCH-EVTcopula approach," International Review of Economics \& Finance, vol. 65, pp. 173-186, 2020.

[66] C. Cao and L. Petrasek, "Liquidity risk in stock returns: an event-study perspective," Journal of Banking \& Finance, vol. 45, pp. 72-83, 2014.

[67] W. Ye, Y. Zhu, Y. Wu, and B. Miao, "Markov regimeswitching quantile regression models and financial contagion detection," Insurance: Mathematics and Economics, vol. 67, pp. 21-26, 2016.
[68] A. Pais and P. A. Stork, "Contagion risk in the Australian banking and property sectors," Journal of Banking \& Finance, vol. 35, no. 3, pp. 681-697, 2011.

[69] X. Fan, Y. Wang, and D. Wang, "Network connectedness and China's systemic financial risk contagion-an analysis based on big data," Pacific-Basin Finance Journal, vol. 64, no. 11, pp. 1013-1035, 2020.

[70] K. Giesecke and S. Weber, "Cyclical correlations, credit contagion, and portfolio losses," Journal of Banking \& Finance, vol. 28, no. 12, pp. 3009-3036, 2004.

[71] P. Jorion and G. Zhang, "Credit contagion from counterparty risk," The Journal of Finance, vol. 64, no. 5, pp. 2053-2087, 2009.

[72] X. Sui and L. Li, "Guarantee network model and risk contagion," Chaos, Solitons \& Fractals, vol. 106, pp. 323-329, 2018.

[73] B. Chakrabarty and G. Zhang, "Credit contagion channels: market microstructure evidence from lehman brothers' bankruptcy," Financial Management, vol. 41, no. 2, pp. 320-343, 2012.

[74] S. Turnbull, "The pricing implications of counterparty risk for non-linear credit products," The Journal of Credit Risk, vol. 1, no. 4, pp. 3-30, 2005.

[75] M. Zhang, J. He, and S. Li, "Interbank lending, network structure and default risk contagion," Physica A: Statistical Mechanics and Its Applications, vol. 493, pp. 203-209, 2018.

[76] M. G. Hertzel and M. Officer, "Industry contagion in loan spreads," Journal of Financial Economics, vol. 103, no. 3, pp. 493-506, 2012.

[77] M. Shen, "A review of the literature on enterprise mentoring: a perspective of social capital theory," Open Journal of Business and Management, vol. 8, no. 2, pp. 892-901, 2020.

[78] D. J. Watts and S. H. Strogatz, "Collective dynamics of "small-world" networks," Nature, vol. 393, no. 6684, pp. 440-442, 1998.

[79] Y. Yang, H. J. Wang, and G. Wang, "Understanding crowdfunding processes: a dynamic evaluation and simulation approach," Journal of Electronic Commerce Research, vol. 17, no. 1, pp. 47-65, 2016.

[80] N. Dew, S. Read, S. D. Sarasvathy, and R. Wiltbank, "Effectual versus predictive logics in entrepreneurial decisionmaking: differences between experts and novices," Journal of Business Venturing, vol. 24, no. 4, pp. 287-309, 2009.

[81] H. Hoang and B. Antoncic, "Network-based research in entrepreneurship," Journal of Business Venturing, vol. 18, no. 2, pp. 165-187, 2003.

[82] I. Dén-Nagy, "Trust and social capital research in hungarian economic sociology, 1995-2012. A literature review," Corvinus Journal of Sociology and Social Policy, vol. 4, no. 1, pp. 113-127, 2013.

[83] S. K. Kim, S. J. Shin, J. Shin, and D. R. Miller, "Social networks and individual creativity: the role of individual differences," The Journal of Creative Behavior, vol. 52, no. 4, pp. 285-296, 2016.

[84] J. Larson, "The weakness of weak ties for novel information diffusion," Applied Network Science, vol. 2, no. 1, 2017.

[85] X. Lv, N. Li, X. Xu, and Y. Yang, "Understanding the emergence and development of online travel agencies: a dynamic evaluation and simulation approach," Internet Research, vol. 1, no. 2, pp. 4-24, 2020.

[86] Q. Xu, L. Zhou, and Q. Chen, "Optimal pricing decision of fashion apparel considering experiential service and design enhancement," Complexity, vol. 2020, Article ID 9505120, 11 pages, 2020. 
[87] P. H. Douglas, "The cobb-douglas production function once again: its history, its testing, and some new empirical values," Journal of Political Economy, vol. 84, no. 5, pp. 903-915, 1976.

[88] C. Pang and Y. Wang, "Stock pledge, risk of losing control and corporate innovation," Journal of Corporate Finance, vol. 60, p. 101534, 2020.

[89] C. Park, "Network and agent dynamics with evolving protection against systemic risk," Complexity, vol. 2020, Article ID 2989242, 16 pages, 2020.

[90] D. W. Taylor, O. Jones, and K. Boles, "Building social capital through action learning: an insight into the entrepreneur," Education Training, vol. 46, no. 5, pp. 226-235, 2004.

[91] X.-C. Yin and H. Liu, "Social capital and subjective wellbeing of rural women in China," Asia Pacific Journal of Social Work and Development, vol. 30, no. 1, pp. 15-31, 2019.

[92] P. Bonacich, "Factoring and weighting approaches to status scores and clique identification," The Journal of Mathematical Sociology, vol. 2, no. 1, pp. 113-120, 1972.

[93] T. Chuluun, A. Prevost, and A. Upadhyay, "Firm network structure and innovation," Journal of Corporate Finance, vol. 44, pp. 193-214, 2017.

[94] D. Audretsch, X. Guo, A. Hepfer, H. Menendez, and X. Xiao, "Ownership, productivity and firm survival in China," Economia e Politica Industriale, vol. 43, no. 1, pp. 67-83, 2016.

[95] L.-W. Liang, C.-P. Cheng, and Y. Lin, "Determinants of banking efficiency and survival in taiwan with consideration of the real management cost," Emerging Markets Finance and Trade, vol. 56, no. 5, pp. 1003-1023, 2018.

[96] Q. Qian, Y. Yang, J. Gu, and H. Feng, "Information authenticity, spreading willingness and credit risk contagion - a dual-layer network perspective," Physica A: Statistical Mechanics and Its Applications, vol. 536, p. 122519, 2019.

[97] P. Augustin, H. Boustanifar, J. Breckenfelder, and J. Schnitzler, "Sovereign to corporate risk spillovers," Journal of Money, Credit and Banking, vol. 50, no. 5, pp. 857-891, 2018.

[98] T. Chen, B. Xiao, and H. Liu, "Credit risk contagion in an evolving network model integrating spillover effects and behavioral interventions," Complexity, vol. 2018, Article ID 1843792, 16 pages, 2018.

[99] W. Zhang, X. Zhuang, J. Wang, and Y. Lu, "Connectedness and systemic risk spillovers analysis of Chinese sectors based on tail risk network," The North American Journal of Economics and Finance, vol. 54, Article ID 101248, 2020.

[100] I. Nica, "Simulation of financial contagion effect using the NetLogo software at the level of the banking network," Theoretical and Applied Economics, vol. 3, no. 624, pp. 55-74, 2020.

[101] L. A. Braunstein, X. H. E. Zhang, Stanley, and L. D. Valdez, "Modeling risk contagion in the venture capital market: a multilayer network approach," Complexity, vol. 2019, Article ID 9209345, 11 pages, 2019.

[102] G. Katriel, "Convergence to an exponential wealth distribution in a random market model," Applicable Analysis, vol. 93, no. 6, pp. 1256-1263, 2013.

[103] C. W. Scherer and H. Cho, "A social network contagion theory of risk perception," Risk Analysis, vol. 23, no. 2, pp. 261-267, 2003.

[104] X. Zhang, L. Feng, Y. Berman, N. Hu, and H. Eugene Stanley, "Exacerbated vulnerability of coupled socio-economic risk in complex networks," EPL (Europhysics Letters), vol. 116, no. 1, p. 18001, 2016.
[105] B. M. Parsons, "The effects of risk, beliefs, and trust in education policy networks: the case of autism and special education," Policy Studies Journal, vol. 48, no. 1, 2018.

[106] F. Bloch, G. Genicot, D. Ray, F. Bloch, G. Genicot, and D. Ray, Bureau for Research and Economic Analysis of Development Informal Insurance in Social Networks, 2005.

[107] A. Habib and M. M. Hasan, "Social capital and corporate cash holdings," International Review of Economics \& Finance, vol. 52, pp. 1-20, 2017.

[108] T. J. Rowley, "Moving beyond dyadic ties: a network theory of stakeholder influences," Academy of Management Review, vol. 22, no. 4, pp. 887-910, 1997.

[109] S. P. Ferris, D. Javakhadze, and T. Rajkovic, "An international analysis of CEO social capital and corporate risktaking," European Financial Management, vol. 25, no. 1, pp. 3-37, 2017.

[110] Y. Ma, X. Jing, and Z. Huang, "Research on the optimization path of China's smes credit guarantee ecological environment," Ekoloji, vol. 28, no. 107, pp. 1761-1766, 2019.

[111] W. Dbouk, Y. Fang, L. Liu, and H. Wang, "Do social networks encourage risk-taking? Evidence from bank CEOs," Journal of Financial Stability, vol. 46, pp. 107-121, 2019.

[112] H. Wamba, "Social capital and access of the Africans' SMEs to the banking credit: evidence from Cameroon," La Revue Des Sciences de Gestion, vol. 48, no. 260, pp. 11-12, 2013.

[113] N. Boubakri, Powerful CEOs and Their Impact on Corporate Performance, Wiley-Blackwell, Hoboken, NJ, USA, 2011.

[114] H. Panta, "Does social capital influence corporate risk-taking?," Journal of Behavioral and Experimental Finance, vol. 26, p. 100301, 2020.

[115] P. Bossaerts, S. Suzuki, and J. P. O’Doherty, "Perception of intentionality in investor attitudes towards financial risks," Journal of Behavioral and Experimental Finance, vol. 23, pp. 189-197, 2019.

[116] S. Jiang and H. Fan, "Credit risk contagion coupling with sentiment contagion," Physica A: Statistical Mechanics and Its Applications, vol. 512, pp. 186-202, 2018.

[117] M. L. Granados and A. M. Rivera, "Assessing the value dimensions of social enterprise networks," International Journal of Entrepreneurial Behavior \& Research, vol. 24, no. 3, pp. 734-754, 2018.

[118] J. W. Peltier and G. M. Naidu, "Social networks across the SME organizational lifecycle," Journal of Small Business and Enterprise Development, vol. 19, no. 1, pp. 56-73, 2012.

[119] R. M. Teixeira, T. Andreassi, M. A. Köseoglu, and F. Okumus, "How do hospitality entrepreneurs use their social networks to access resources? Evidence from the lifecycle of small hospitality enterprises," International Journal of Hospitality Management, vol. 79, pp. 158-167, 2019.

[120] M. S. Dahl and O. Sorenson, "Home sweet home: entrepreneurs' location choices and the performance of their ventures," Management Science, vol. 58, no. 6, pp. 1059-1071, 2012. 